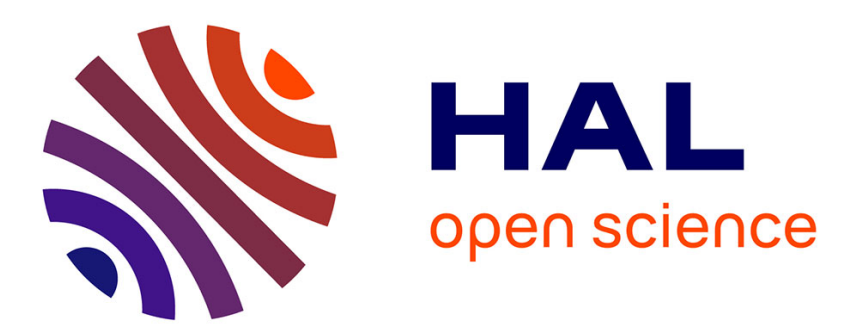

\title{
Dynamic anisotropic elastic properties of a claystone under variable loading direction and saturation
}

D Grgic, A Giraud, L Schoumacker

\section{To cite this version:}

D Grgic, A Giraud, L Schoumacker. Dynamic anisotropic elastic properties of a claystone under variable loading direction and saturation. Geophysical Journal International, 2018, 10.1093/gji/ggy417 . hal-02981393

\section{HAL Id: hal-02981393 \\ https://hal.univ-lorraine.fr/hal-02981393}

Submitted on 5 Jan 2022

HAL is a multi-disciplinary open access archive for the deposit and dissemination of scientific research documents, whether they are published or not. The documents may come from teaching and research institutions in France or abroad, or from public or private research centers.
L'archive ouverte pluridisciplinaire HAL, est destinée au dépôt et à la diffusion de documents scientifiques de niveau recherche, publiés ou non, émanant des établissements d'enseignement et de recherche français ou étrangers, des laboratoires publics ou privés. 


\title{
Dynamic anisotropic elastic properties of a claystone under variable loading direction and saturation
}

\author{
D. Grgic ${ }^{\circledR}$, A. Giraud and L. Schoumacker \\ Université de Lorraine, CNRS, GeoRessources, F-54000 Nancy, France.E-mail: dragan.grgic@univ-lorraine.fr
}

Accepted 2018 October 6. Received 2018 September 10; in original form 2018 May 07

\begin{abstract}
S U M M A R Y
Ultrasonic $P$ - and $S$-wave velocities were measured continuously on a transversely isotropic clayrock during uniaxial compression tests, with different hydrous conditions $\left(h_{r}=100,90\right.$, 81 and 66 per cent) and loading directions (parallel and perpendicular to the bedding plane), to determine the dynamic stiffness tensor and velocity anisotropy, characterize microcracking damage and assess the influence of water saturation. The evolution of $P$ - and $S$-wave velocities reproduces the shape and features of the stress-strain curves remarkably well. The elastic anisotropy, initially significant, reduces markedly during perpendicular loading and increases during parallel loading. For the perpendicular loading direction, the evolution of strains, wave velocities and dynamic elastic coefficients show a significant axial compaction due to the stiffening of the rock structure (phyllosilicate sheets and grains contacts) and closure of preexisting microcracks aligned with the bedding plane. Then, induced microcracks propagate in the vertical loading direction and their opening is parallel to the horizontal bedding plane. For the parallel loading direction, the axial compaction is smaller and the behaviour is more linear since pre-existing microcracks remain open and mineral structure is less stiffened. Then, induced microcracks are aligned within the vertical bedding planes (i.e. planes of weakness) and their horizontal opening is perpendicular to these planes. The dynamic Young's modulus is larger than the static one (up to 2.2 times) before loading. For the perpendicular loading direction, the ratio of dynamic to static moduli decreases continuously. This suggests an increase in hydraulic connectivity of the pore space in this direction due to induced microcracks, which is expected to reduce the anisotropy of Biot's coefficients tensor. For the parallel loading direction, the ratio is almost constant. This suggests that the increase in pore space connectivity associated with induced microcracks occurs mainly within the bedding plane, which is expected to increase the anisotropy of Biot's tensor. The uniaxial compressive strength, which is systematically lower in the parallel direction than in the perpendicular direction, decreases globally with the increase in water saturation. For the parallel loading direction, the drying globally stiffens the rock. Contrariwise, for the perpendicular loading direction, the drying unusually softens the rock and increases initial $P$-wave anisotropy. This could be explained by the axial compaction of cracks along horizontal bedding planes induced by the initial drying.
\end{abstract}

Key words: Permeability and porosity; Geomechanics; Body waves; Seismic anisotropy; Wave propagation; Microstructures.

\section{INTRODUCTION}

The monitoring of damage development and the study of the mechanisms of cracks initiation and growth in rocks are subjects of great interest in many engineering applications such as underground manmade structures (e.g. mines and quarries, storage cavities for radioactive waste, $\mathrm{CO}_{2}, \mathrm{H}_{2}$ ), especially to characterize the EDZ (excavation damaged zone). Here the example of collapse of underground (rooms and pillars) iron mines in Lorraine (North-Eastern France) is considered. Many studies of the mechanisms underlying the short- and long-term brittle behaviour of iron ore pillars were reported in the literature (e.g. Grgic \& Amitrano 2009; Eslami et al. 2010; Eslami et al. 2012; Grgic et al. 2013; Grgic \& Giraud 2014). However, the roof of rooms, which is made of a few meters thick 
layer of claystone, have attracted much less attention despite their potential impact on the stability of the underground mine structure. We report here the results of experimental study of anisotropic elastic properties of an anisotropic claystone under uniaxial compressive stress, thanks to an ultrasonic wave velocities monitoring system. Uniaxial compressive tests in the laboratory simulate the stress state at the roof of excavations.

Indeed, in the brittle regime (i.e. low temperature and confining pressure) relevant to shallow environments such as underground manmade constructions, microcracking damage is considered to be the main mechanism of rock deformation (Bieniawski 1967; Kranz 1983; Atkinson 1984; Atkinson \& Meredith 1987; Jeong et al. 2007). In the laboratory, the evolution in the state of damage under mechanical loading can be analysed using ultrasonic (US) wave velocity measurements, which are very sensitive to crack initiation and growth in rocks (Sayers et al. 1990; Sayers \& Kachanov 1995; Schubnel \& Guéguen 2003; Fortin et al. 2005; Sarout \& Guéguen 2008a; Sarout \& Guéguen 2008b; Eslami et al. 2010; Eslami et al. 2012; Sarout et al. 2017). Most of such experimental studies on claystone (shales, argillites) samples reported in the literature were performed under hydrostatic loading (e.g. Johnston \& Toksöz 1980; Jones \& Wang 1981; Lo et al. 1986; Vernik \& Nur 1992; Johnston \& Christensen 1995; Hornby 1998; Stanley \& Christensen 2001; Meléndez-Martínez \& Schmitt 2016) or triaxial/uniaxial loading (e.g. Podio et al. 1968; Dewhurst \& Siggins 2006; Dodds et al. 2007; Sarout et al. 2007; Delle Piane et al. 2011; Dewhurst et al. 2011; Sarout et al. 2014) under undrained saturated or dry conditions. However, there are no experimental studies under partially saturated conditions due to the notoriously peculiar properties of claystones: low permeability, chemical sensitivity to water, fissility due to preferred alignment of phyllosilicate minerals (clays, micas). In this study, a relatively high permeability $\left(\sim 2 \times 10^{-19} \mathrm{~m}^{2}\right.$ in the bedding-perpendicular direction) claystone (argillaceous and carbonated siltstone) is tested under different hydrous conditions. Indeed, underground manmade constructions correspond to shallow environments in which hydrous conditions can evolve with time, i.e. from full saturation before workings to partial saturation induced by artificial ventilation of the galleries.

For the purpose of this study, a laboratory apparatus was developed to monitor ultrasonic wave velocities with different directions of propagation and polarization on a single rock plug strains under uniaxial loading and controlled hygrometry simultaneously. Unlike similar experiments reported in the literature, ultrasonic wave velocities are measured continuously throughout the entire duration of the mechanical experiment. This technique allows the characterization of the five dynamic elastic coefficients of the transversely isotropic claystone from a single sample. This reduces the number of experiments on differently oriented samples usually necessary and minimizes the impact of natural heterogeneity between samples of the same formation. Two main directions for the uniaxial stress were investigated, namely, parallel and perpendicular to the bedding plane, which is assumed to be the plane of elastic symmetry. For each direction, four samples with different hydrous states (equilibrated at a relative humidity $h_{r}=66,81,90$ and 100 per cent) were tested.

The main objectives of these experiments are to determine the dynamic stiffness tensor and velocity anisotropy during uniaxial loading in order to characterize microcracking damage and assess the influence of water content. Furthermore, differences between static and dynamic elastic moduli will be examined. The comprehension of these differences is of great interest in many geophysical and geomechanical applications (e.g. seismicity, unconventional oil and gas reservoirs, underground manmade structures) because conventional static measurements in the laboratory are not always possible due to the scarcity of rock samples. Therefore, dynamic measurements are often more accessible from seismic surveys of sonic well logs in the field. For example, many authors (e.g. Vanheerden 1987; Christaras et al. 1994; Brotons et al. 2016; Asef $\&$ Farrokhrouz 2017) have proposed equations relating static and dynamic modulus values.

\section{MATERIAL AND METHODS}

\subsection{Description of the studied claystone}

In the Lorraine region of France, which represents the eastern border of the Paris sedimentary basin, the sedimentary formation (Aalenian, Middle Jurassic) rich in iron ore is inclined a few degrees to the southwest and has a $60 \mathrm{~m}$ maximal thickness and a $250 \mathrm{~m}$ maximal depth. It includes more than 10 iron ore layers, which are 3-7 $\mathrm{m}$ thick and separated by multimetric intercalated layers made of argillaceous and carbonated siltstone. The cohesion is ensured alternately by a silty and clayey dark cement and by a calcareous light cement. Mineralogical analyses (scanning electron microscopy, X-ray diffraction) have shown the presence of clay minerals (illite, iron chlorite and kaolinite), ferruginous oolites, iron oxydes, quartz, feldspars, pyrite, flake micas and fragments of shells, phosphates and tourmaline. Scanning electron microscopy observations are presented in Fig. 1; images show aligned clay particles, carbonate minerals and pyrite (in white colour). The rock texture (i.e. fabric) corresponds to bedding planes, which are quasihorizontal in situ. So the studied claystone is a vertical transversely isotropic (VTI) material, with a vertical axis of rotational symmetry and the bedding plane is the plane of isotropy. The macroscopic anisotropy results from the preferential alignment along the bedding plane of very anisotropic minerals, i.e. phyllosilicates such as clays (whose platelets are grouped together to form clay particles) and micas, and cracks. The studied rock is highly anisotropic but, unlike shales, this siltstone is not fissile i.e. breaks along planes of weakness (parallel laminae or bedding) into thin sheets due to preferred alignment of phyllosilicate minerals. Indeed, the abundance of carbonate cement ensures a good cohesion to this claystone.

The bulk (total) porosity $\phi$ of this claystone is about 13 per cent. Mercury intrusion is a porosimetry technique allowing the determination of the distribution of the entrance radii of pores (throats). The porous network, represented in Fig. 2, is unimodal and composed of pore throat radii between 0.002 and $0.1 \mu \mathrm{m}$ in size. The intrinsic water permeability $k$ was determined in a triaxial cell using the Darcy's law (under 1 MPa water pressure and 1.5 MPa confining pressure) on a sample perpendicular to the bedding. The value is about $2 \times 10^{-19} \mathrm{~m}^{2}$ and it is expected that it is higher in the bedding-parallel direction. Fig. 2 also shows water sorption curves of the studied claystone: liquid saturation $S_{l}$ versus relative humidity $h_{r}$ and capillary pressure $p_{c}$. The relation between $h_{r}$ and $p_{c}$ is given by the Kelvin law, which represents the isothermal equilibrium between liquid water and its vapour in a porous medium:

$\ln \frac{p_{v}}{p_{v}^{0}}=\ln h_{r}=\frac{-p_{c} M_{v}}{R T \rho_{l}}$,

where $h_{r}$ is the relative humidity, $p_{v}$ is the partial pressure of water vapour, $p^{0}{ }_{v}$ is the vapour pressure under thermodynamic equilibrium, $p_{c}$ is the capillary pressure, $\rho_{l}$ is the density of liquid water, $R$ is the gas constant, $M_{v}$ is the molar mass of water vapour and $T$ is the absolute temperature. 

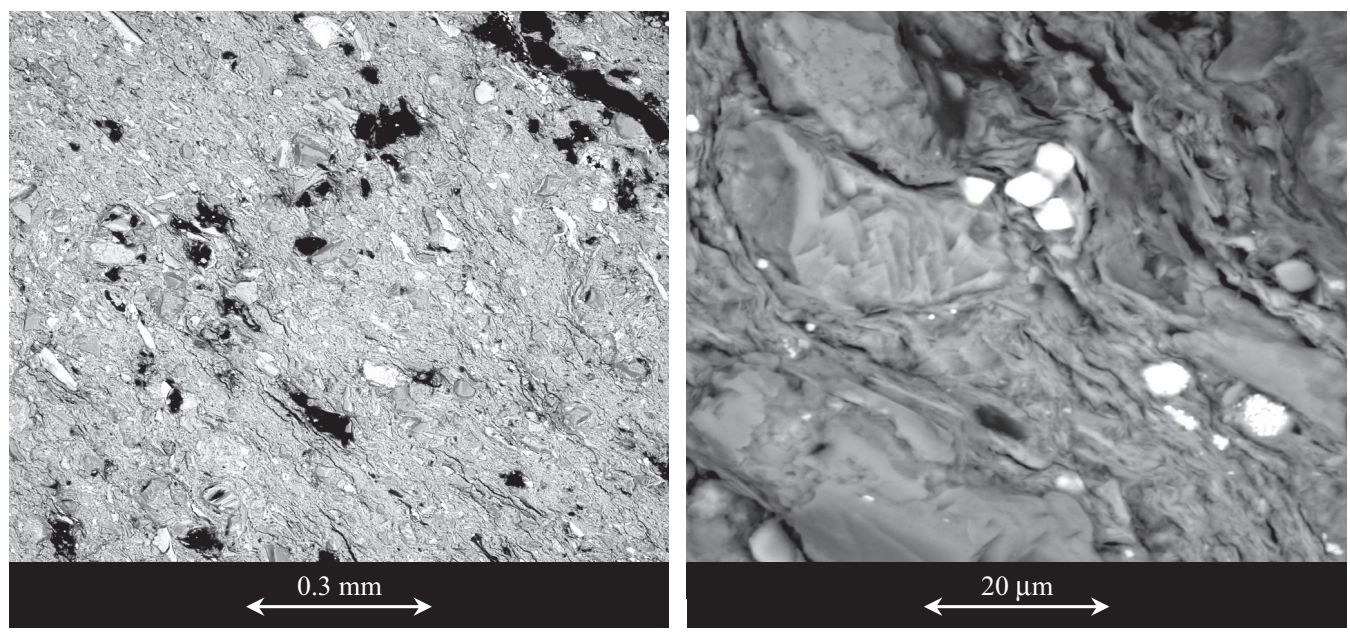

Figure 1. Scanning electron microscopy observations on crack surfaces showing textural organization of the claystone. Low (left-hand side) and high (right-hand side) magnification images.
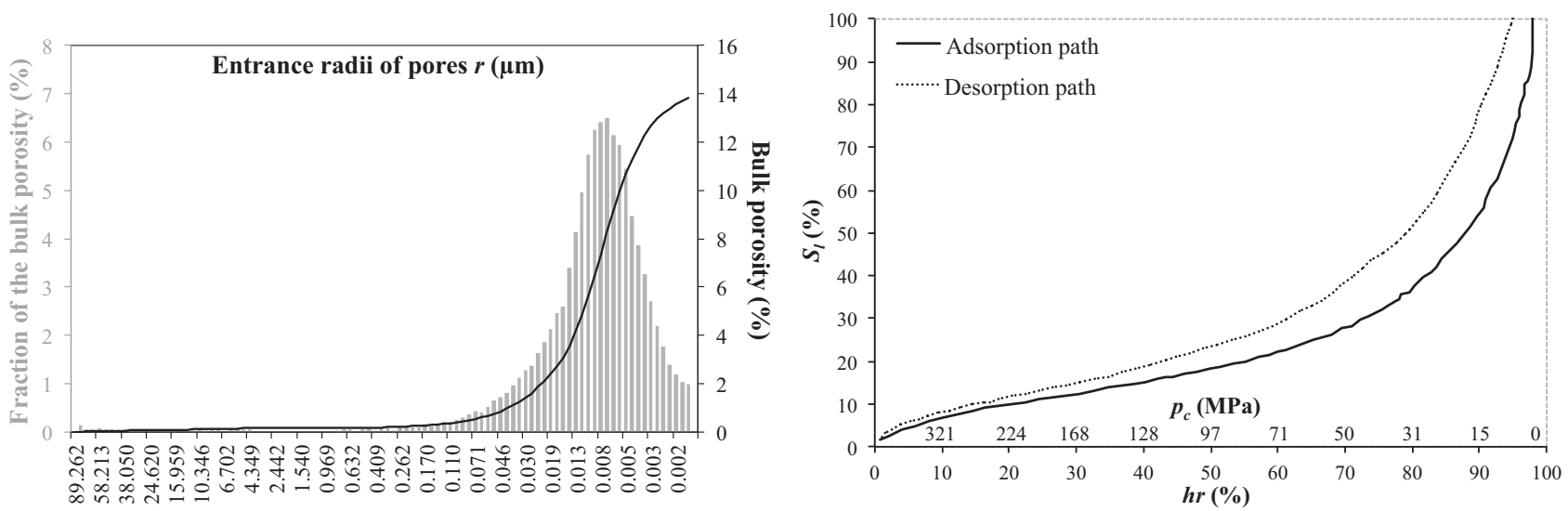

Figure 2. Left-hand panel: distribution of entrance radii of pores (porous spectrum) for total porosity of the claystone obtained from mercury intrusion porosimetry (first injection). Right-hand panel: water suction curves of the claystone (liquid saturation $S_{l}$ versus relative humidity $h_{r}$ and capillary pressure $p_{\mathrm{c}}$ ).

\subsection{Theoretical considerations: dynamic stiffness coefficients for VTI}

For VTI materials, such as the studied claystone, the characterization of the five independent elastic coefficients requires the knowledge of five independent US wave phase velocities: $V P_{0^{\circ}}$ for the beddingparallel (i.e. $\theta=0^{\circ}$ ) $P$-wave velocity, $V P_{45^{\circ}}$ for the off-axis ( $45^{\circ}$-tobedding) $P$-wave velocity, $V P_{90^{\circ}}$ for the bedding-perpendicular (i.e. $\left.\theta=90^{\circ}\right) P$-wave velocity, $V S h_{0^{\circ}}$ for the bedding-parallel velocity of horizontally polarized $S$ - wave and $V S v_{0^{\circ}}$ for the bedding-parallel velocity of vertically polarized $S$-wave. The five independent $C_{\mathrm{ij}}$ coefficients (in Voigt notation) are calculated using the well-known Christoffels equations (Tsvankin 2001):

$C_{11}=\rho V P_{0^{\circ}}^{2} \quad C_{33}=\rho V P_{90^{\circ}}^{2}$

$C_{44}=\rho V S v_{0^{\circ}}{ }^{2} \quad C_{66}=\rho V S h_{0^{\circ}}{ }^{2}$,

where $\rho$ is the volumetric mass density of the material.

Concerning the off-axis measurement of the $P$-wave, group or phase velocity question has to be considered. It has been shown by many authors in the literature (e.g. Berryman 1979; Thomsen 1986; Hornby 1998; Tsvankin 2001; Dewhurst \& Siggins 2006) that wave velocities measured in laboratory in anisotropic media are group velocities but for those travelling along principal axes group velocities are equal to phase velocities. Actually, measuring phase or group velocities depends on a number of parameters, namely, the size of the sensors with respect to the propagation distance, the orientation of the off-axis propagation direction, the magnitude of anisotropy, etc. (Dellinger \& Vernik 1994; Sarout et al. 2015). Pwave velocity measured at an oblique angle $\left(45^{\circ}\right.$-to-bedding in our case) is then a group velocity and the correct determination of $C_{13}$ requires the calculation of the corresponding phase velocity $V P_{\theta}$ (see Appendix for details).

From the five independent $C_{\mathrm{ij}}$ coefficients, the five classical engineering elastic constants (Young's moduli $E_{11}$ and $E_{33}$, Poisson's ratios $v_{12}, v_{13}$ or $v_{31}$ and shear coefficient $G_{31}$ ) may be calculated as follows (Podio et al. 1968), $D$ being the determinant:

$$
\begin{aligned}
E_{11} & =\frac{D}{C_{11} C_{33}-C_{13}^{2}} \quad E_{33}=\frac{D}{C_{11}^{2}-C_{12}^{2}} \\
D & =\left|\begin{array}{lll}
C_{11} & C_{12} & C_{13} \\
C_{12} & C_{22} & C_{13} \\
C_{13} & C_{13} & C_{33}
\end{array}\right| \\
v_{12} & =\frac{C_{12} C_{33}-C_{13}^{2}}{C_{11} C_{33}-C_{13}^{2}} \quad v_{13}=\frac{C_{13}\left(C_{11}-C_{12}\right)}{C_{11} C_{33}-C_{13}^{2}} \\
v_{31} & =\frac{C_{13}}{C_{11}+C_{12}} .
\end{aligned}
$$


For comparison and analysis of the anisotropy, it is useful to calculate the three dimensionless anisotropy parameters $(\varepsilon, \gamma, \delta)$ initially introduced by Thomsen (1986) from elastic coefficients:

$\varepsilon=\frac{C_{11}-C_{33}}{2 C_{33}} \quad \gamma=\frac{C_{66}-C_{44}}{2 C_{44}}$
$\delta=\frac{\left(C_{13}+C_{44}\right)^{2}-\left(C_{33}-C_{44}\right)^{2}}{2 C_{33}\left(C_{33}-C_{44}\right)}$

$\varepsilon$ and $\gamma$ quantify $P$ wave anisotropy and $S$-wave anisotropy, respectively. $\delta$ is a critical factor governing the geometry of the $P$-wave wavefront. These three anisotropy parameters reduce to zero in the case of isotropy.

\subsection{Samples preparation}

Four cylindrical samples (height $=100 \mathrm{~mm}$, diameter $=50 \mathrm{~mm}$ ) were cored for each principal direction of stress loading, parallel and perpendicular to the bedding plane. Before proceeding, let us define the reference frame $\left(x_{1}, x_{2}, x_{3}\right)$. For a transversely isotropic cylindrical sample, $\left(x_{1}, x_{2}\right)$ is the horizontal bedding plane of symmetry and $x_{3}$ is the axis of symmetry (Fig. 3). The convention of positive compressions for stresses and strains is used.

The deformations were measured with strain gages (two strain gages are mounted facing each other on the cylindrical samples for each direction): one axial strain and one lateral strain are measured for the samples cored perpendicularly to the bedding plane, one axial strain and two lateral strains for the samples cored in parallel to the bedding plane. Ultrasonic wave velocities were measured with 0.5 inches ultrasonic transducers (frequency: $150 \mathrm{kHz}$ for $P$-waves and $100 \mathrm{kHz}$ for $S$-waves). The position of the strain gages and the piezoceramic transducers is shown in Fig. 3 for both principal directions.

Once instrumented, each sample was exposed to different relative humidities: $h_{r}=100$ per cent (water saturated), 90, 81 and 66 per cent. The relative humidity $h_{r}$, and therefore the capillary pressure in the porous medium, is imposed using the saturated salt solutions method (ISO standard 483, 2005): the partial pressure of water vapour depends on the chemical composition of the salt solution. Four hydrous conditions were imposed to the claystone in this study:

(1) $h_{r}=100$ per cent (water saturated); $p_{c}=0 \mathrm{MPa}$,

(2) $h_{r}=90$ per cent $\left(h_{r}\right.$ imposed by salt solution $\mathrm{ZnSO}_{4}, 7 \mathrm{H}_{2} \mathrm{O}$ ); $p_{c}=14.3 \mathrm{MPa}$,

(3) $h_{r}=81$ per cent $\left(h_{r}\right.$ imposed by salt solution $\left.\left(\mathrm{NH}_{4}\right) 2 \mathrm{SO}_{4}\right)$; $p_{c}=28.5 \mathrm{MPa}$,

(4) $h_{r}=66$ per cent $\left(h_{r}\right.$ imposed by salt solution $\left.\mathrm{NaNO}_{2}\right)$; $p_{c}=56.2 \mathrm{MPa}$.

These hydrous conditions were imposed to the samples until equilibrium, which lasted up to 3 months for some samples. Hydrous equilibrium was detected by controlling the weight evolution of the samples. At equilibrium, the weight of each sample was measured, thus allowing the calculation of the volumetric mass density (eq. 2).

Tested samples are called as follows:

(1) Direction of the applied uniaxial stress $\sigma_{33}$ perpendicular $\perp$ to the bedding plane (rock fabric): A $\left(\perp h_{r}=66\right.$ per cent), B $(\perp$ $h_{r}=81$ per cent $), \mathrm{C}\left(\perp h_{r}=90\right.$ per cent $), \mathrm{D}\left(\perp h_{r}=100\right.$ per cent $)$.

(2) Direction of the applied uniaxial stress $\sigma_{11}$ parallel // to the bedding plane (rock fabric): E (// $h_{r}=66$ per cent), F (// $h_{r}=81$ per cent), $\mathrm{G}\left(/ / h_{r}=90\right.$ per cent), $\mathrm{H}\left(/ / h_{r}=100\right.$ per cent).

\subsection{Experimental procedure}

Once equilibrated with its hydrous environment, each sample was tested mechanically in a hermetically sealed uniaxial compression cell in which the same hydrous conditions were maintained. The loading path corresponds to a uniaxial compression with increasing unloading-reloading cycles (the stress was half unloaded for each cycle). Before each unloading phase, a relaxation phase of $15 \mathrm{~min}$ was applied to dissipate viscous effects (e.g. viscoelasticity). For all samples, a sufficiently low deformation rate $\left(6 \mu \mathrm{m} \mathrm{min}^{-1}\right)$ was used to ensure drained conditions during the uniaxial compression test. This is justified by the relatively high intrinsic permeability of the studied siltstone $\left(k \sim 2 \times 10^{-19} \mathrm{~m}^{2}\right)$ and by the uniaxial loading condition, which allows the water to be drained in all directions.

To verify this assumption for the saturated case, one can use the solution given by Coussy (2004) or Cheng (2016) for this quasistatic problem of poroelasticity. The overpressurization of the saturating fluid due to an extra loading vanishes, owing to the diffusion process of the fluid towards the boundary which remains drained. The characteristic time $t_{c}$ for the dissipation of the pore pressure throughout the specimen writes as a function of the consolidation coefficient $c$ :

$$
\begin{aligned}
t_{c}=\frac{L_{c}{ }^{2}}{c} & c=\kappa M \frac{\lambda+2 \mu}{\lambda+2 \mu+b^{2} M} \quad \kappa=\frac{k}{\eta} \\
b=1-\frac{K}{K_{s}} & M=\frac{K_{u}-K}{b^{2}},
\end{aligned}
$$

where $L_{c}$, the characteristic length, is the largest distance that the pore pressure diffusion front needs to travel (half diameter of the core $=0.025 \mathrm{~m}), \kappa\left(=2 \times 10^{-16} \mathrm{~m}^{3} \mathrm{~s} \mathrm{~kg}^{-1}\right)$ is the permeability coefficient (or mobility coefficient), $\eta\left(=1 \times 10^{-3} \mathrm{~kg} \mathrm{~m}^{-1} \mathrm{~s}^{-1}\right)$ is the fluid dynamic viscosity, $M\left(=3.5 \times 10^{9} \mathrm{~Pa}\right)$ is the Biot's modulus, $b(=0.9)$ is the Biot's coefficient, $K\left(=7.7 \times 10^{9} \mathrm{~Pa}\right)$ is the drained bulk modulus, $K_{u}\left(=10.5 \times 10^{9} \mathrm{~Pa}\right)$ is the undrained bulk modulus, $K_{S}\left(=7.1 \times 10^{10} \mathrm{~Pa}\right)$ is the solid matrix bulk modulus, $\lambda\left(=3.2 \times 10^{9} \mathrm{~Pa}\right)$ is the first drained Lamé coefficient, $\mu$ $\left(=4.9 \times 10^{9} \mathrm{~Pa}\right)$ is the second Lamé coefficient (shear modulus). These values have been measured during this work.

Then, the consolidation coefficient $c=5.7 \times 10^{-7} \mathrm{~m}^{2} \mathrm{~s}^{-1}$ and the characteristic time of diffusion $t_{c} \sim 18 \mathrm{~min}$. Since $t_{c}$ is much lower than the duration of the experiments on saturated samples $\mathrm{H}$ and $\mathrm{D}$ ( 2 and $5 \mathrm{hr}$, respectively), one can consider that conditions are drained during the uniaxial compression tests on saturated samples. Indeed, in analytic poroelastic solutions, the fluid flow is close to the stationary state when $t=t_{c}$ (see among others Coussy 2004; Cheng 2016), which corresponds to the drained case (= asymptotic solution of the fluid pressure). For the partially saturated case, the linear equations of the saturated case do not apply. However, because of the presence of gas, which is more compressible than liquid water, the conditions are closer to the drained case than to the undrained case where the incompressible fluid (i.e. liquid water) is trapped.

US wave velocities were measured using the standard Ultrasonic Pulse Transmission technique (Birch 1960), which consists in measuring the traveltime of a solitary elastic pulse between a source and a receiver piezoceramic ultrasonic transducers held in contact with the rock sample. Sinusoidal pulses are supplied by a generator and a multiplexer allows the automatic and quasi-simultaneous (i.e. a few microseconds) measurement of velocities on 24 channels. The sampling rate is $100 \mathrm{MHz}$, corresponding to a precision of $\pm 0.01 \mu \mathrm{s}$. Hence, ultrasonic wave velocities are measured continuously throughout the entire duration of the mechanical experiment (uniaxial compression test), unlike similar experiments found in the 

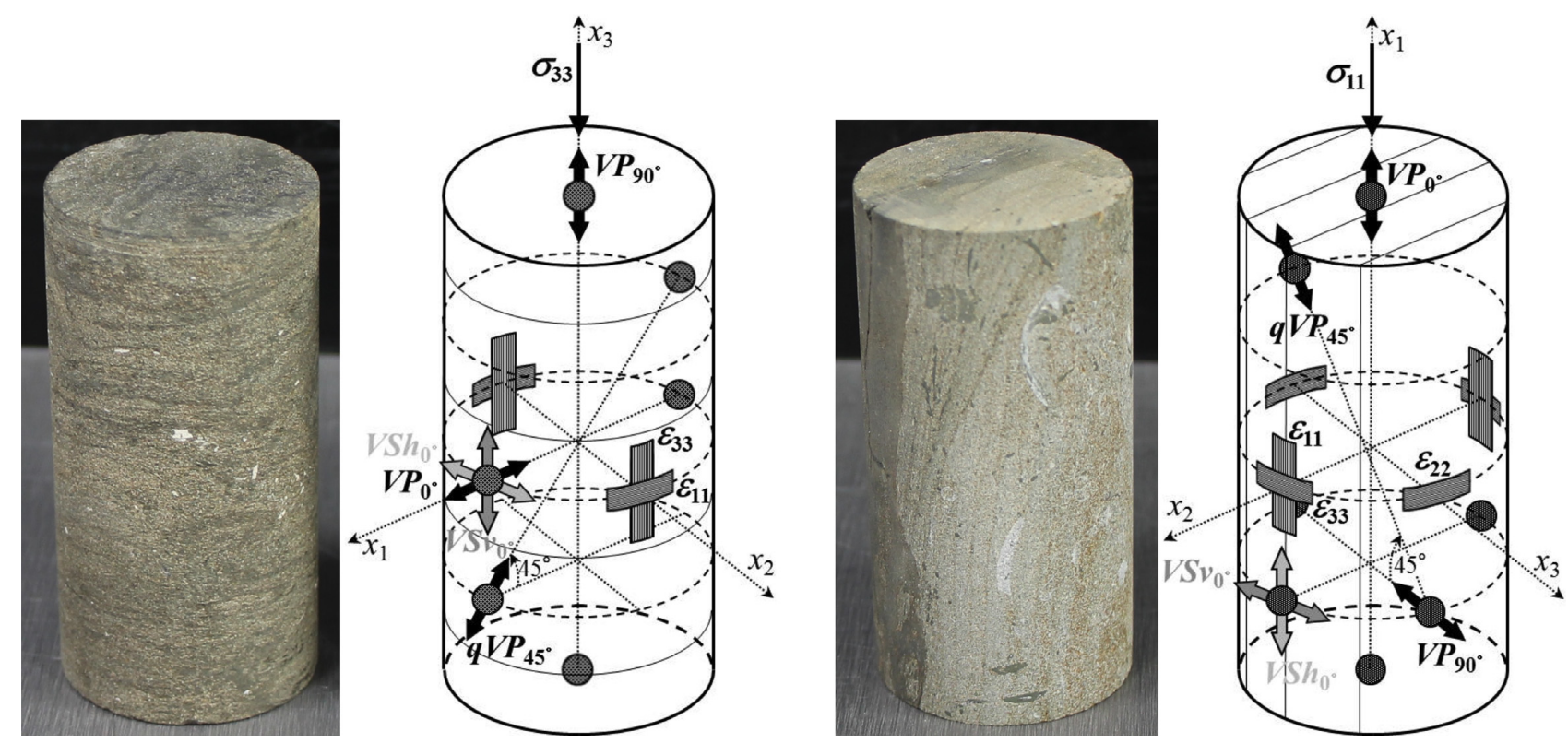

Figure 3. Position of strain gages and piezoceramic transducers (both directions of propagation and polarization are indicated for each wave velocity) on transversely isotropic cylindrical samples for both principal directions of the applied uniaxial stress: perpendicular (left-hand side) and parallel (right-hand side) to the bedding plane.

literature (e.g. Dewhurst \& Siggins 2006; Sarout et al. 2007; Delle Piane et al. 2011).

The dynamic elastic properties were determined with the following procedure:

(1) Times of flights (TOF) of ultrasonic waves were semiautomatically picked from a threshold corresponding to 20 per cent of the first peak amplitude of the signal. This (high) percentage was selected because it avoids the noise and, then, gives the best results. Fig. 4 shows examples of waveforms taken at the beginning of the experiment on sample A ( $\perp h_{r}=66$ per cent) and corresponding TOF.

(2) Velocities $V P_{0^{\circ}}, V P_{90^{\circ}}, V P_{45^{\circ}}, V S h_{0^{\circ}}$ and $V S v_{0^{\circ}}$ are determined from the arrival time and the distance between each source and receiver transducers. This distance was continuously corrected by taking into account material deformations (measured with strain gages).

(3) $C_{11}, C_{33}, C_{44}$ and $C_{66}$ are calculated from eq. (2). Knowing $V P_{45^{\circ}}$, the experimental quasi $P$-wave group velocity at $45^{\circ}$ to the principal axes, and the ray path angle $\phi=45$ per cent corresponding to the angle between the axis of symmetry $x_{3}$ and the line joining the transmitter and receiver transducers, $C_{13}, V P_{\theta}$ and $\theta$ can then be calculated by solving simultaneously eqs (2)-(4) in the Appendix. A nonlinear simultaneous equation solver was used for this purpose. The calculation of the five independent $C_{\mathrm{ij}}$ coefficients was performed taking into account the variation of the volumetric mass density of the material. This parameter was continuously corrected by taking into account rock deformations.

\section{DIRECT EXPERIMENTAL RESULTS}

Only results obtained on samples A ( $\perp h_{r}=66$ per cent), for the bedding perpendicular direction of loading, and $\mathrm{G}\left(/ / h_{r}=90\right.$ per cent) for the bedding parallel direction of loading, are presented in Sections 3.1 and 3.2. The results obtained on other samples are consistent with these results. Experiment on sample E $\left(/ / h_{r}=66\right.$ per cent) was not successful, so results will not be presented and discussed.

As already proposed by Yin (1992) or Hornby (1998), an error analysis of the ultrasonic pulse transmission technique can be carried out. This analysis includes the precision of the sample size measurements ( 0.0001 per cent with strain gages) and the precision of the traveltime picking equal to the sampling rate of $0.01 \mu \mathrm{s}$. In our experimental case, the relative error in the velocity measurements is approximately 0.05 to 0.15 per cent, depending on the wave type and propagation direction.

\subsection{Deformations and elastic wave velocities}

Figs 5 and 6 represent the evolution of strains $\varepsilon_{11}=\varepsilon_{22}, \varepsilon_{33}$ and $\varepsilon_{v}$ (volumetric deformation) and $P$ - and $S$-wave velocities $V P_{90^{\circ}}$, $V P_{0^{\circ}}, V P_{45^{\circ}}$ and $V P_{\theta}$ for the off-axis $P$-wave, $V S v_{0^{\circ}}$ and $V S h_{0^{\circ}}$ during uniaxial compression stress-cycling test on samples A $(\perp$ $h_{r}=66$ per cent) and G (// $h_{r}=90$ per cent), respectively. The maximal difference between the group velocity $V P_{45^{\circ}}$ and the phase velocity magnitude $V P_{\theta}$ of the off-axis $P$-wave is about $170 \mathrm{~m} \mathrm{~s}^{-1}$ for sample A and $50 \mathrm{~m} \mathrm{~s}^{-1}$ for sample $\mathrm{G}$. This difference induces significant corrections of the coefficient $C_{13}$.

The initial values of $P$ - and $S$-wave velocities show a significant initial anisotropy of the claystone at the macroscale. Generally speaking, anisotropy of wave velocities is due to the presence of anisotropic minerals (clay particles, micas), preferential orientation of voids (cracks and pores) and textural characteristics (bedding). For both directions of loading, the evolution of $P$ - and $S$ wave velocities reproduces very remarkably the shape and features of the stress-strain curves, including hysteresis of the unloadingreloading cycles. 

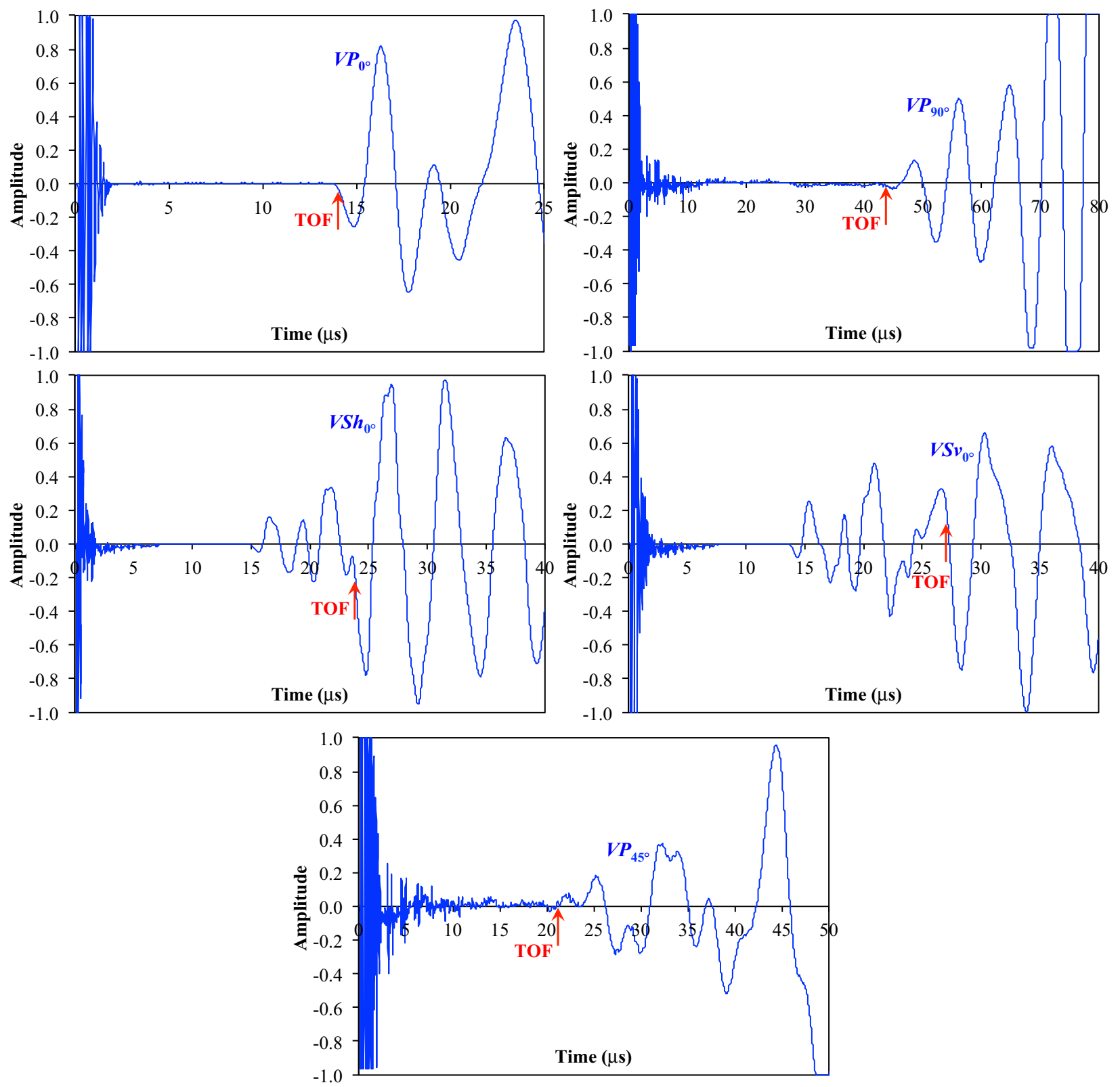

Figure 4. Examples of waveforms taken at the beginning of the experiment on sample $\mathrm{A}$ ( $\perp h_{r}=66$ per cent) with corresponding TOF.

\subsection{Dynamic elastic coefficients and dimensionless anisotropy factors}

Figs 7 and 8 represent the evolution of dynamic elastic coefficients $\left(C_{11}, C_{33}, C_{44}, C_{66}\right.$ and $\left.C_{13}\right)$ and dimensionless anisotropy factors $(\varepsilon$, $\gamma$ and $\delta$ ), whereas Figs 9 and 10 represent the evolution of dynamic engineering constants, i.e. Young's moduli $\left(E_{11}, E_{33}\right)$ and Poisson's ratio $\left(v_{13}, v_{31}\right.$ and $\left.v_{12}\right)$, during uniaxial compression stress-cycling tests on samples $\mathrm{A}\left(\perp h_{r}=66\right.$ per cent $)$ and $\mathrm{G}\left(/ / h_{r}=90\right.$ per cent $)$.

For the loading direction perpendicular to the horizontal bedding plane (sample A), the axial Young's modulus $E_{33}$ increases significantly and continuously. The lateral Young's modulus $E_{11}$ also increases, but less markedly, and shows a very small decrease at the peak stress. Poisson's ratio $v_{31}$ (and $v_{13}$ ) decreases with the uniaxial loading because of the material stiffening, whereas $v_{12}$ increases.
For the loading direction parallel to the bedding plane (sample G), the axial Young's modulus $E_{11}$ increases continuously. The lateral Young's modulus $E_{33}$ also increases, but less markedly. The evolution of Poisson's ratios is the same as for sample A.

The initial anisotropy of the studied claystone is significant. For the perpendicular loading direction, $P$-wave anisotropy $\varepsilon$ reduces significantly under uniaxial loading whereas $S$-wave anisotropy $\gamma$ barely decreases. For the parallel loading direction, $P$-wave anisotropy $\varepsilon$ increases whereas $S$-wave anisotropy $\gamma$ is almost constant. As already shown by Sarout et al. (2007) and Dewhurst \& Siggins (2006) from similar tests on shales, $\delta$ is the most sensitive parameter. When unloading, the anisotropy does not recover its initial value because the mechanisms of plastic deformation and damage are almost irreversible. 


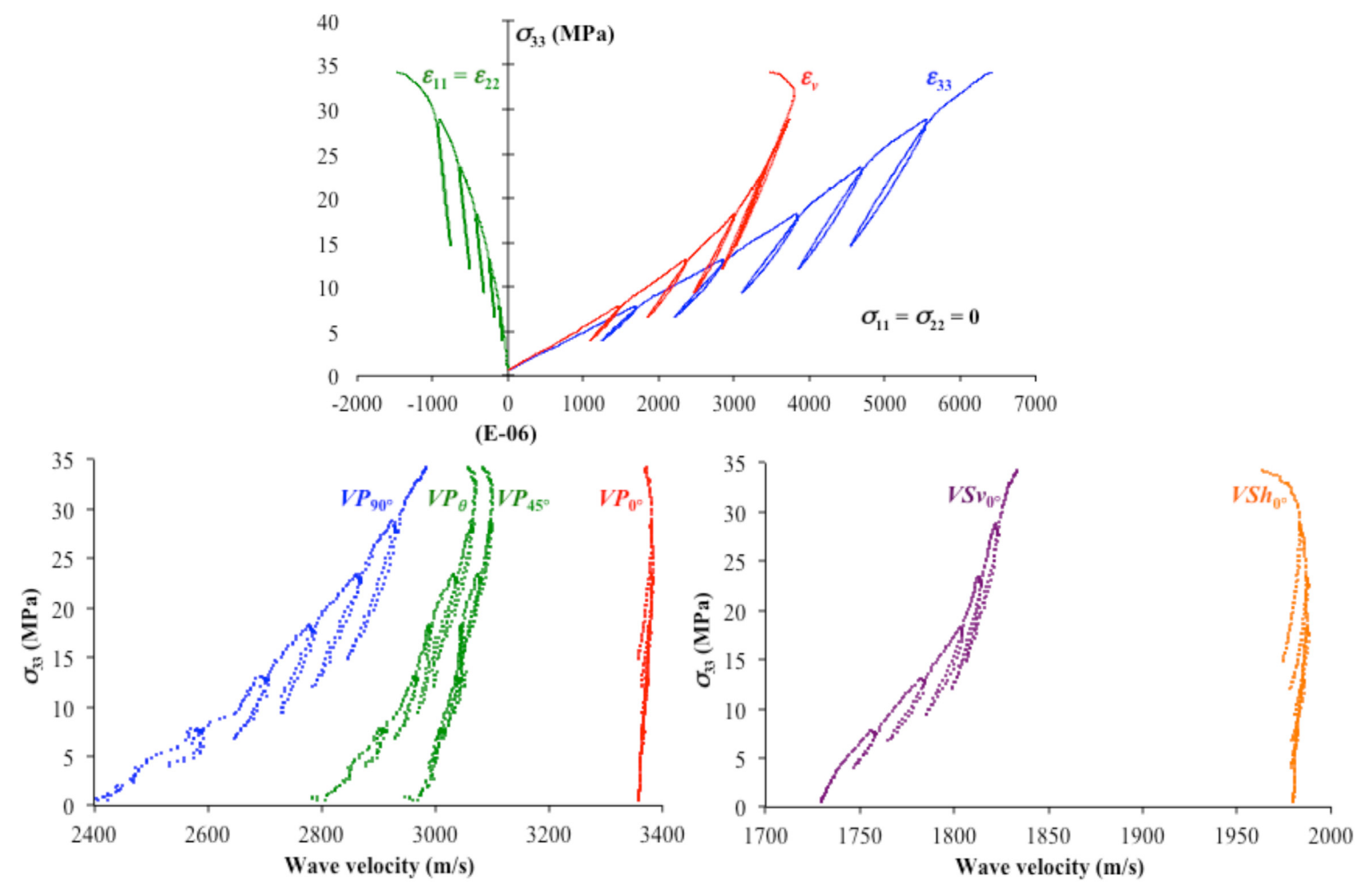

Figure 5. Evolution of strains and P- and S-wave velocities of sample A: direction of the applied uniaxial stress perpendicular to the bedding plane, $h_{r}=66$ per cent.

\section{DISCUSSION}

\subsection{Mechanisms of deformation and damage}

First, let us consider the linear part of stress-strains curves (Figs 5 and 6), i.e. before unstable growth (or coalescence) of microcracks. For sample A $\left(\perp h_{r}=66\right.$ per cent) with perpendicular loading direction (Fig. 5), wave velocities increase with stress from the beginning of the loading. The axial Young's modulus $E_{33}$ increases significantly and continuously (Fig. 9). This behaviour is usually ascribed to the stiffening of the crystals structure (tightening of clay and micas sheets aligned with the bedding plane) and grains contacts, closure of pre-existing cracks and crack-like pores aligned with the bedding plane, and porosity loss. These 'plastic' deformation mechanisms are almost irreversible, which is confirmed by stiffer unloading-reloading curves. Porosity loss is negligible in our case since mechanical compaction of a microporous (cf. Fig. 2) and stiff rock like the studied claystone would require very high stresses, out of range compared to in-situ stresses and current applications. This is confirmed by the volumetric strain curve $\varepsilon_{v}$ (Fig. 5 ), which shows small compaction (max. $\sim 0.38$ per cent at the dilatancy threshold) during uniaxial loading. The porosity loss can be assessed using the theory of poroelasticity (Coussy 2004) which gives the following equation under drained conditions: $\mathrm{d} \phi=b d \varepsilon_{v}$. Then, the change in porosity ( $\sim 0.34$ per cent) is almost equal to the change in volumetric strain, which means that pore space is way more compliant than the solid matrix. $V P_{90^{\circ}}$, i.e. the axial $P$-wave velocity, reproduces very well the evolution of the axial strain $\varepsilon_{33}$. It increases the most in absolute terms $(+25$ per cent $)$ because it propagates in parallel to the uniaxial stress $\sigma_{33}$ direction, along which the material is the most compacted, and perpendicularly to the mineral structure (i.e. bedding plane). $V P_{90^{\circ}}$ shows nonlinear behaviour at low stress that is often related to the closure of pre-existing cracks. $V P_{\theta}$, the off-axis $P$-wave, also increase significantly ( +10 per cent) because it is also affected by the vertical compaction of the claystone. $V S v_{0}$. is also significantly affected ( +6 per cent) because the propagation is parallel to the mineral structure but the polarization is perpendicular. $V P_{0^{\circ}}(+0.6$ per cent $)$, where propagation is parallel to the mineral structure, and $V S h_{0^{\circ}}(+0.4$ per cent), where propagation and polarization are parallel to the material structure, barely increase. For sample G (// $h_{r}=90$ per cent) with parallel loading direction (Fig. 6), only $V P_{0^{\circ}}$, i.e. the longitudinal wave travelling in the axial direction of the sample, increases significantly with the axial stress $\sigma_{11}\left(+5\right.$ per cent). The axial Young's modulus $E_{11}$ also increases continuously (Fig. 10). Compared to sample A $\left(\perp h_{r}=66\right.$ per cent), the increase in axial strain and axial $P$-wave velocity $V P_{0^{\circ}}$ is smaller and the behaviour is linear at low stress because, in this loading direction, pre-existing cracks and crack-like pores aligned with the bedding plane remain open and clay crystals structure is much less stiffened.

Second, let us consider the nonlinear part of stress-strains curves, i.e. from the onset of unstable growth (or coalescence) of microcracks (Figs 5 and 6). This is classically identified from the dilatancy threshold in the volumetric strain curve because it represents the opening of axial microcracks. For sample A $\left(\perp h_{r}=66\right.$ per cent $)$ 

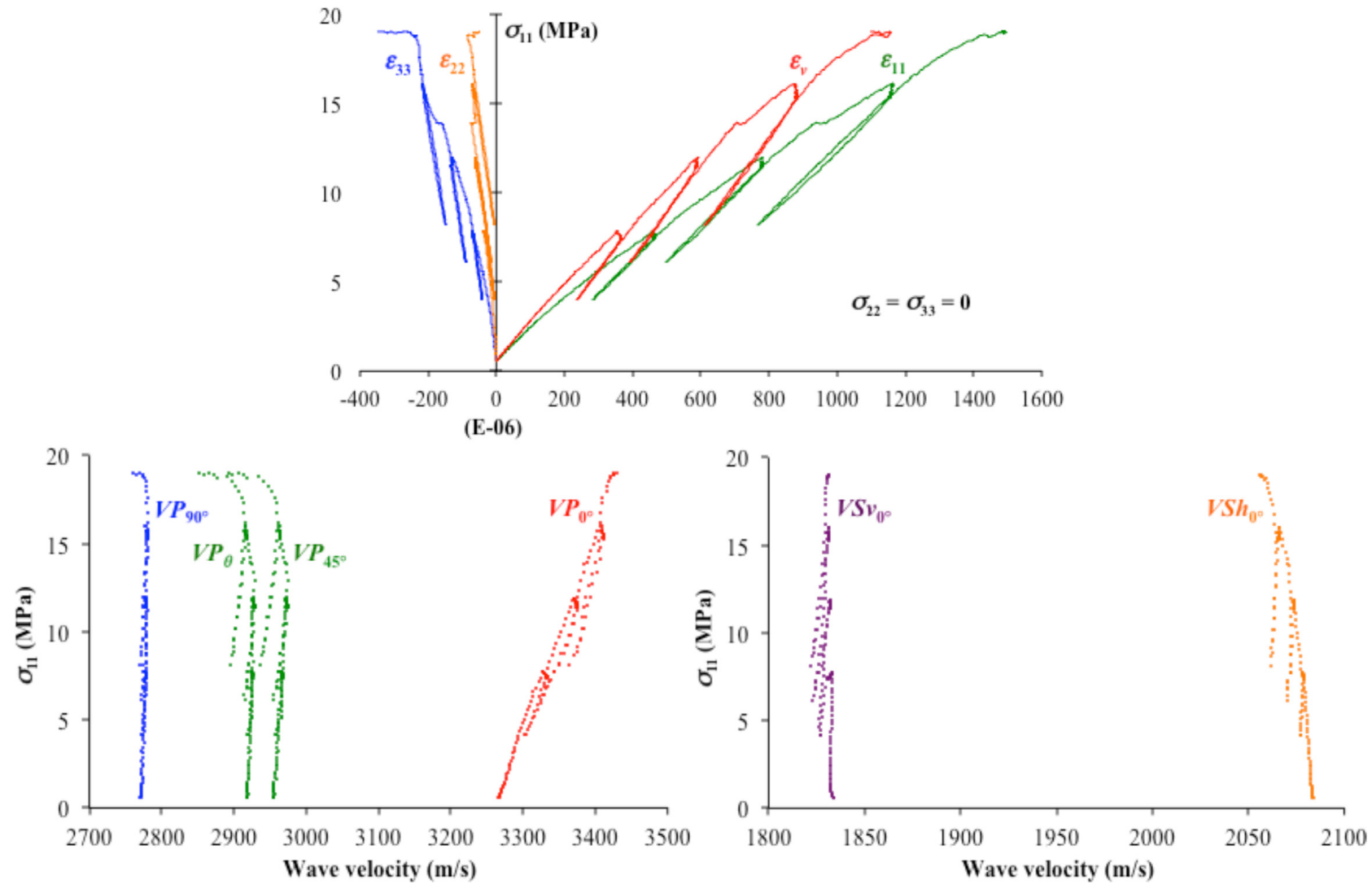

Figure 6. Evolution of strains and P- and S-wave velocities of sample G: direction of the applied uniaxial stress parallel to the bedding plane, $h_{r}=90$ per cent.
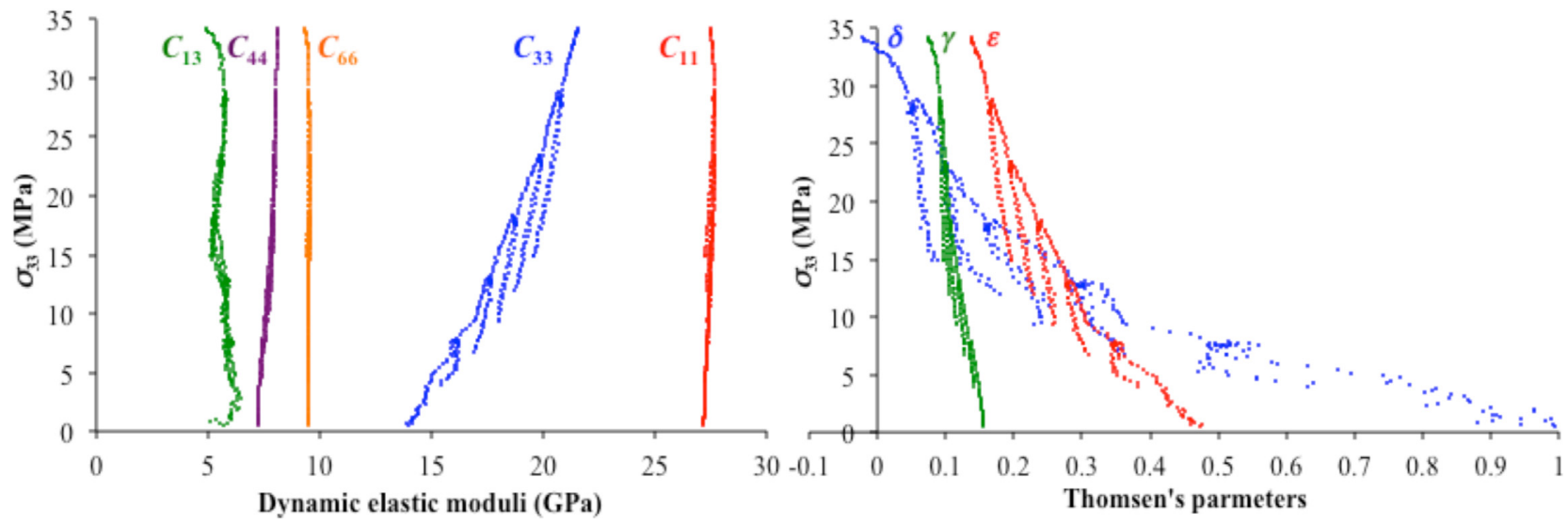

Figure 7. Evolution of dynamic elastic coefficients and dimensionless anisotropy factors of sample A: direction of the applied uniaxial stress perpendicular to the bedding plane, $h_{r}=66$ per cent.

with perpendicular loading direction (Fig. 5), this threshold is visible in both volumetric strain curve and wave velocities curves. Indeed, from this threshold, $V P_{0^{\circ}}, V P_{\theta}$ and $V S h_{0^{\circ}}$ decrease until the macroscopic failure of the sample. $V P_{90^{\circ}}$ and $V S v_{0^{\circ}}$ do not decrease because microcracks propagate in parallel to the vertical axis 3 and their opening is parallel to the horizontal bedding plane (axes 1 and 2). Anisotropic spatial orientation of microcracks has already been shown by many authors from experimental studies (e.g. Zhao 1998; Homand et al. 2000). It was found that the propagation of microcracks is preferentially in a direction close to the loading direction.
For sample $\mathrm{G}\left(/ / h_{r}=90\right.$ per cent) with parallel loading direction (Fig. 6), the onset of unstable growth of microcracks is not visible in the volumetric strain curve but it is visible for other tested samples in this direction $(\mathrm{F}, \mathrm{H})$. This onset is visible for all samples in the lateral strain curve $\varepsilon_{33}$ which starts to increase whereas $\varepsilon_{22}$ barely changes during the whole loading. This means that the opening of microcracks is perpendicular to the vertical bedding plane (axes 1 and 2) and parallel to the horizontal axis 3 . This is confirmed by the decrease of $P$-wave velocities $V P_{90^{\circ}}$ and $V P_{\theta} . V P_{0^{\circ}}$ and $V S h_{0^{\circ}}$ do not decrease because of this orientation of microcracks. However, 

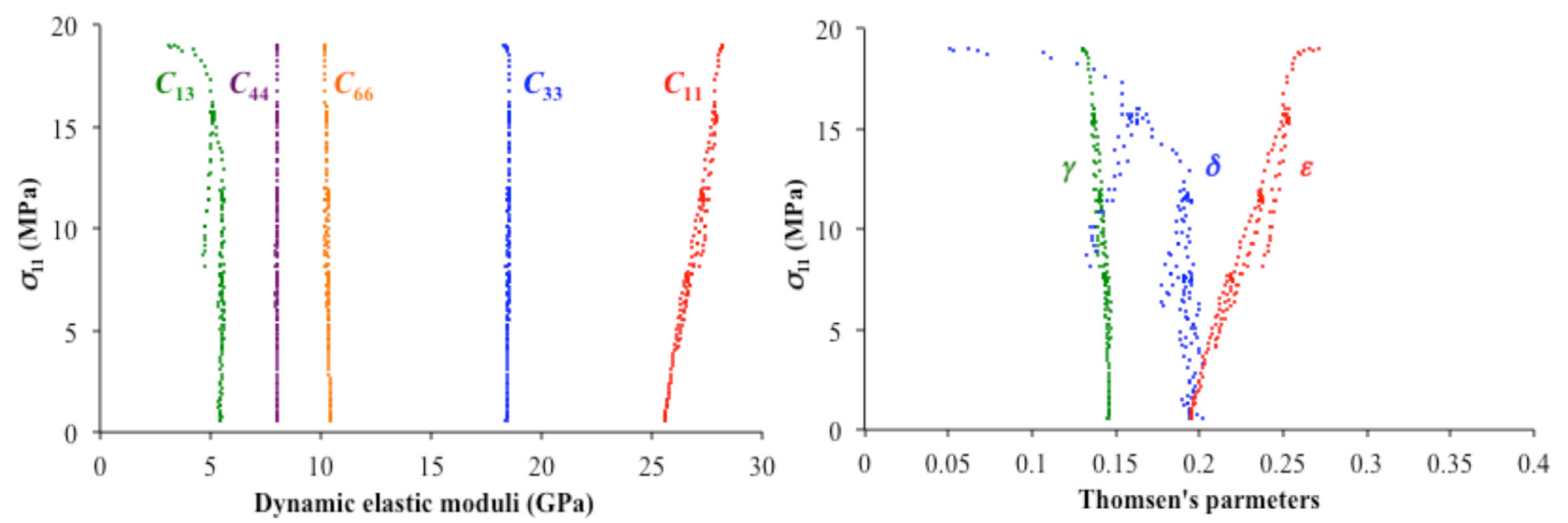

Figure 8. Evolution of dynamic elastic coefficients and dimensionless anisotropy factors of sample G: direction of the applied uniaxial stress parallel to the bedding plane, $h_{r}=90$ per cent.
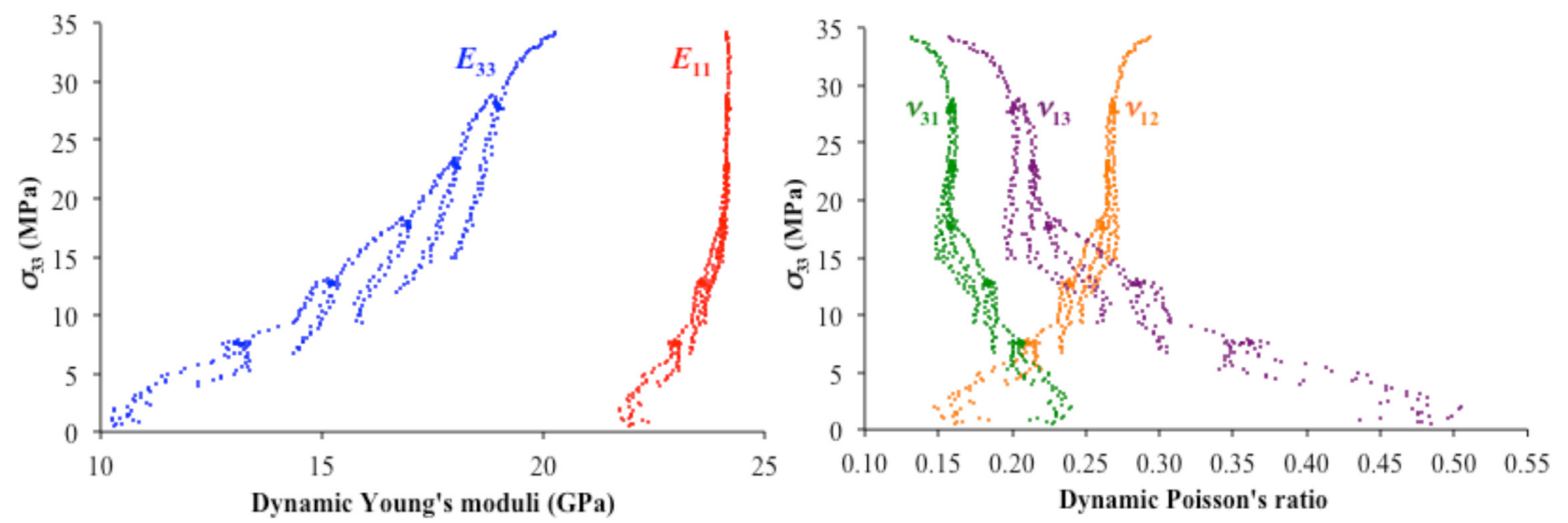

Figure 9. Evolution of dynamic engineering constants $\left(E_{11}, E_{33}, v_{13}, v_{31}\right.$ and $\left.v_{12}\right)$ of sample A: direction of the applied uniaxial stress perpendicular to the bedding plane, $h_{r}=66$ per cent.
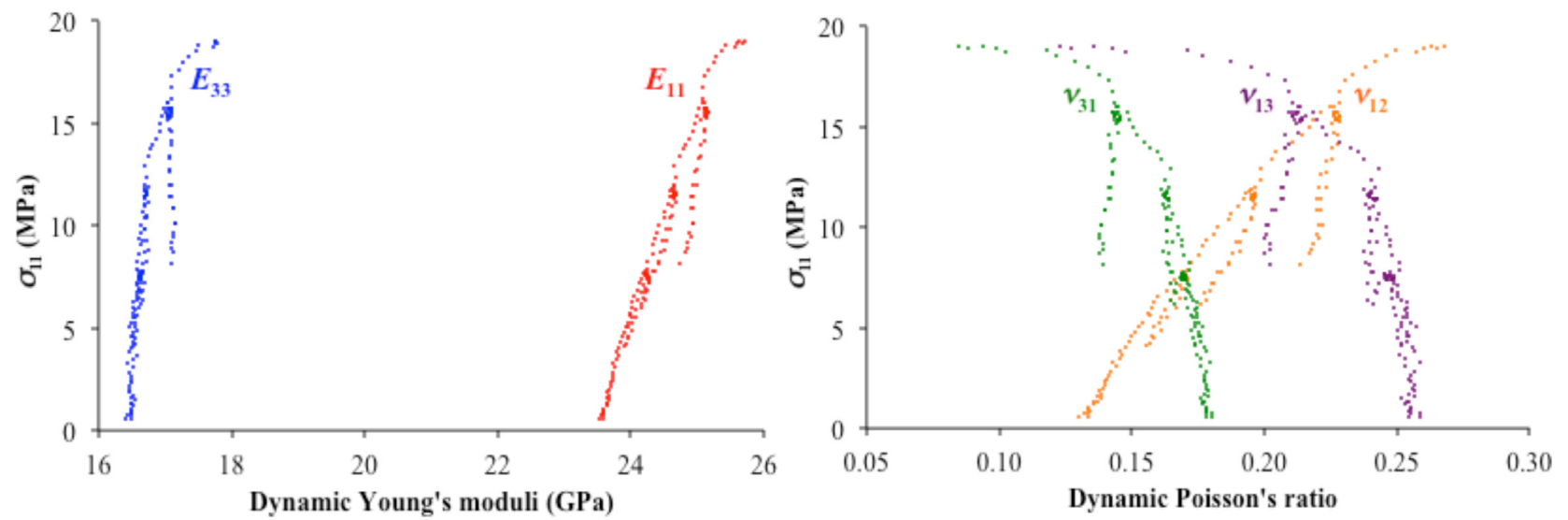

Figure 10. Evolution of dynamic engineering constants $\left(E_{11}, E_{33}, v_{13}, v_{31}\right.$ and $\left.v_{12}\right)$ of sample G: direction of the applied uniaxial stress parallel to the bedding plane, $h_{r}=90$ per cent. 
the $S$-wave velocity $V S v_{0}$. does not decrease and seems to not be influenced by the horizontal opening of microcracks. For this parallel loading direction, microcracks have probably a shape close to a strongly oblate spheroid (ellipsoid of revolution), with the symmetry axis perpendicular to the vertical bedding plane (axes 1 and 2 ) and parallel to the symmetry axis $x_{3}$ of the material. It is then speculated that induced microcracks are aligned within the vertical bedding planes (i.e. weakness planes) and their horizontal opening is perpendicular to these planes.

Because of these mechanisms of deformation and damage, from the beginning of the loading until the peak stress, the anisotropy of $P$-wave velocities $\varepsilon$ reduces significantly for the perpendicular loading direction and increases for the parallel loading direction (Figs 7 and 8 ). $S$-wave anisotropy $\gamma$ decreases a little for the perpendicular loading direction and is almost constant for the parallel loading direction. Similar results, but less explicit, were already reported in the literature (e.g. Sarout et al. 2007; Delle Piane et al. 2011). Fig. 11 represents the evolution of $V P / V S$ ratios during tests on samples A $\left(\perp h_{r}=66\right.$ per cent $)$ and $\mathrm{G}\left(/ / h_{r}=90\right.$ per cent $)$. For sample $\mathrm{A}\left(\perp h_{r}=66\right.$ per cent), $V P_{90^{\circ} / V S v_{0}}$ increases constantly from the beginning of the loading until the peak stress whereas $V P_{0^{\circ}} V S h_{0^{\circ}}$ remains almost constant except a small increase at the peak stress. For sample $\mathrm{G}\left(/ / h_{r}=90\right.$ per cent), $V P_{0^{\circ}} V S h_{0^{\circ}}$ increases constantly from the beginning of the loading until the peak stress whereas $V P_{90^{\circ}}, V S v_{0} \circ$ remains almost constant except a small decrease at the peak stress. Many authors (e.g. Holt et al. 1991; Jakobsen \& Johansen 2000; Dewhurst et al. 2002; Dewhurst \& Siggins 2006) have already noted, from similar experiments on unsaturated, partly saturated and saturated shales, constant or slightly increasing $V P / V S$ ratios with increasing effective stresses. In our case (Fig. 7), the increase is more pronounced and is limited to the waves affected by the material compaction, i.e. $V P_{90^{\circ}}, V S v_{0^{\circ}}$ for perpendicular loading direction (sample A) and $V P_{0^{\circ}} V S h_{0^{\circ}}$ for parallel loading direction (sample G). These authors found that $P$-wave velocity increases more in absolute terms with increasing uniaxial stress than $S$-wave velocity probably because $S$-waves travelling through clay-rich materials are relatively insensitive to effective stress change below about $25 \mathrm{MPa}$. This can explain why $P$-wave anisotropy $\varepsilon$ evolves much more than $S$-wave anisotropy $\gamma$ (Figs 7 and 8). The significant increase of $V S v_{0}$. for sample A with perpendicular loading (Fig. 5) and the associated little decrease of $\gamma$ (Fig. 7), may be associated with the loss of interlayer water from the mineral structure, as proposed by Dewhurst \& Siggins (2006). Indeed, the presence of bound interlayer water within the mineral structure reduces the bulk density. $V S v_{0}$ 位 significantly affected because the polarization is perpendicular to the mineral structure.

\subsection{Static versus dynamic elastic moduli}

For an ideal elastic material, dynamic and static moduli should be the same but in the case of rocks dynamic moduli are most commonly greater than static moduli. Inelastic mechanisms in quasi-static and dynamic loadings contribute to the observed differences as a function of frequency and amplitude. Wave velocities, and thus elastic moduli, are usually greater in higher frequencies. Pimienta et al. (2016) have shown frequency-dependent variations of Young's modulus on Fontainebleau sandstone and identified two frequency-dependent phenomena related to the drained/undrained and undrained/unrelaxed transitions. Then, the presence of fluid in pores and existing cracks could contribute to these differences. At low frequencies, pore pressure in existing cracks become equal to the outside pore pressure during the travel of compressional $P$-wave and existing crack space contribute to the pore space in the Biot's theory. At high frequencies, however, pore fluid in existing cracks does not equilibrate with rapid pressure oscillations of outside pore fluid and do not contribute to the pore space in the Biot's theory, thus resulting in stiffer rock matrix. However, at high frequencies, the issue is still open due to uncertainties on microstructure, including multiscale nature of pore and cracks space. On the basis of the dynamic poroelastic theory developed by Biot (1962), the limit Biot frequency, which separates inertial and viscous fluid effects, writes:

$f_{b}=\frac{\eta \phi}{2 \pi k \rho_{f}}$,

where $\rho_{f}$ is the fluid (water in our case) density, $\eta$ is the fluid dynamic viscosity, $k$ is the macroscopic intrinsic permeability of the porous medium and $\phi$ is the porosity.

For the studied claystone, the estimated Biot frequency $f_{b} \sim$ $10^{5} \mathrm{MHz}$ is much larger than the experimental perturbation frequency $(100-150 \mathrm{kHz})$. It would mean that for the experimental frequency the saturating water would be in the viscous regime during the crossing of the elastic wave and water pressure relaxation around the travelling wave path may not have enough time to occur. However, as stated by Sarout et al. (2007), this approach is a strong approximation and some phenomena like the real geometry of the void space (i.e. presence of crack-like pores), gas partial saturation (which is the case in our partially saturated samples) may induce squirt-flow extra dissipation phenomena, in both saturated and unsaturated cases. To conclude on this point, at the present it seems not possible, for the studied claystone, to accurately separate pores and cracks contributions to the pore space in the Biot's poroelastic theory.

To compare static and dynamic elastic moduli, the technique used for the determination of the slope of stress-strain curves has to be defined. Dynamic values were measured continuously for almost each stress state. However, static moduli are determined from the slope of stress-strain curves of unloading-reloading cycles performed at different stress states. The slope is calculated over a stress range with two classical methods, secant and tangent. The secant method needs the whole stress range and in our case the stress was half unloaded for each cycle. Therefore during an important unloading, the measure of the secant axial Young's modulus may be affected by the nonlinear (and partially reversible) behaviour at low stresses due to the closure of pre-existing cracks, thus giving an underestimated value. With the tangent method, the slope can be calculated from unloading curves over a small stress variation (1 MPa for example). The tangent method gives then almost 'unloaded' static Young's modulus. Fig. 12 represents the evolution of static axial Young's moduli ( $E_{33}$ for perpendicular loading and $E_{11}$ for parallel loading) for all tested samples with the tangent method. Fig. 13 represents the evolution of dynamic axial Young's moduli ( $E_{33}$ for perpendicular loading and $E_{11}$ for parallel loading) for all tested samples.

The ratio of dynamic to static Young's moduli for all tested samples is compared in Fig. 14. In all cases, the dynamic Young's modulus is obviously larger than the static one (up to 2.2 times). For the perpendicular loading direction and for all hydrous conditions, the ratio decreases continuously from the beginning of loading until the macroscopic failure. This phenomenon could be explained by the development of microcracking damage. Indeed, as said before, at dynamic conditions pore fluid in existing cracks do not equilibrate with rapid pressure oscillations of outside pore 

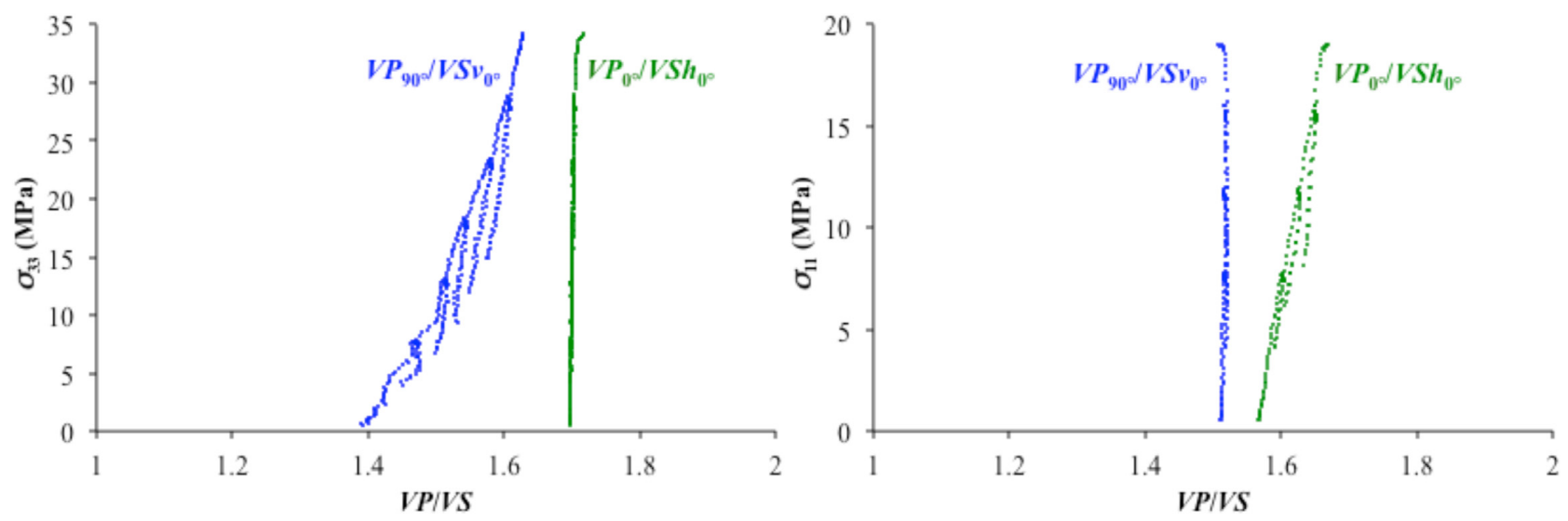

Figure 11. Evolution of $V P / V S$ ratios of sample A $\left(\perp h_{r}=66\right.$ per cent $)$ on the left-hand side and sample $\mathrm{G}\left(/ / h_{r}=90\right.$ per cent $)$ on the right-hand side.
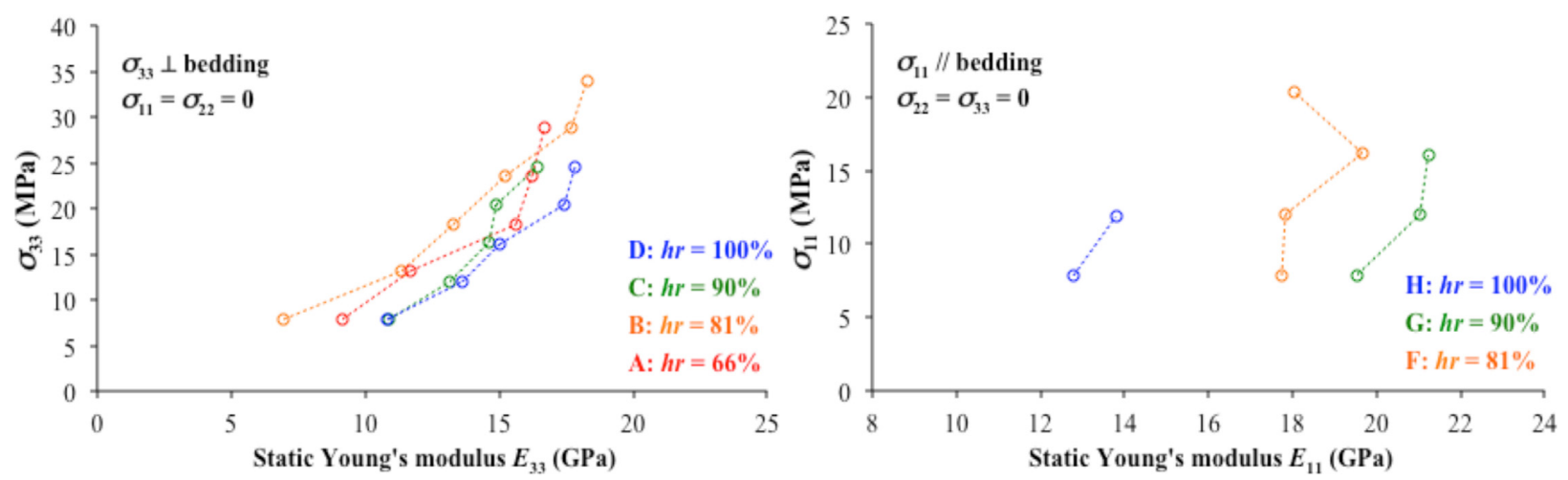

Figure 12. Evolution of static Young's modulus determined with the tangent method on the unloading curve of all tested samples: $E_{33}$ for perpendicular loading and $E_{11}$ for parallel loading.
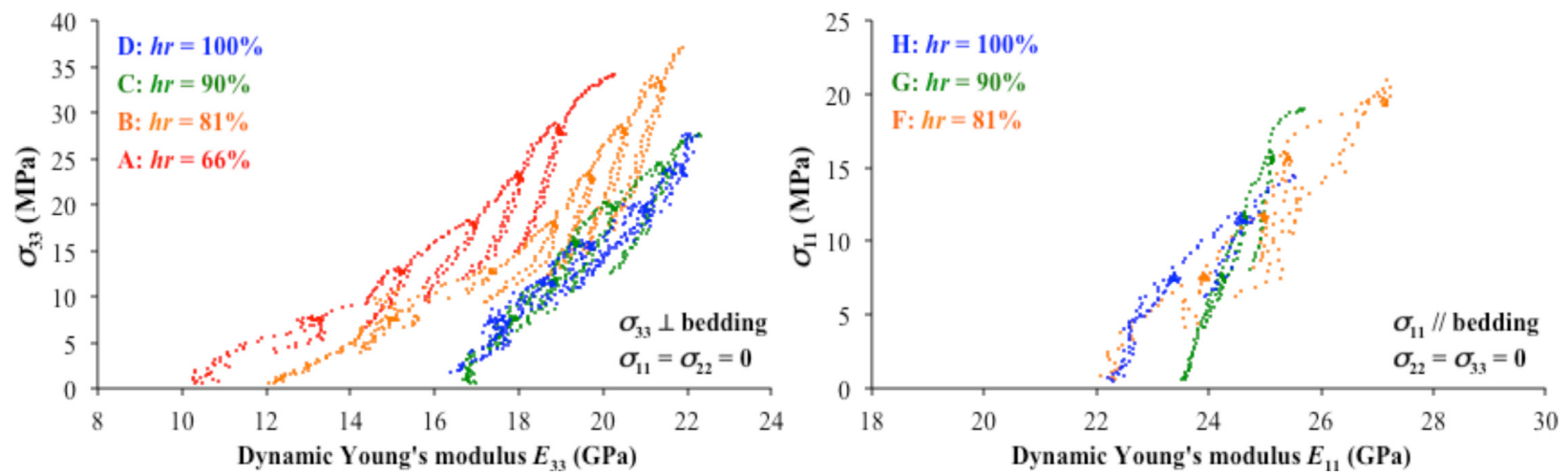

Figure 13. Evolution of dynamic Young's modulus of all tested samples ( $E_{33}$ for perpendicular loading and $E_{11}$ for parallel loading).

fluid and do not contribute to the rest of the pore space in the Biot's theory, thus resulting in stiffer rock matrix. It is then speculated that microcracks that develop during uniaxial loading perpendicularly to the bedding plane increase pore space connectivity. The microcracks, with initially sealed pore fluid because of the high frequency ultrasonic perturbation, would then hydraulically connect to the rest of the pore space, thus reducing the effective stiffness of the rock matrix. For the parallel loading direction, the evolution of the ratio does not show the same tendency; it is almost constant. This would mean that microcracks that develop increase pore space connectivity mainly within bedding planes (i.e. weakness planes), where they are localized, but not in the whole material.
Moreover, tensorial physical properties, such as Biot's coefficient, should respect material symmetry and be transversely isotropic in the case of claystones. Micromechanical modelling predicts (e.g. Giraud et al. 2008) that a quasi-isotropic Biot's tensor with a transversely isotropic matrix and drained elasticity tensor is possible if pores are spherical or randomly distributed in orientation. The initial anisotropy of Biot's tensor is then mainly due to the preferential alignment of crack-like pores and cracks along bedding planes. Micromechanical modelling also show that the development of oriented and connected cracks increases the anisotropy degree of the Biot's tensor. See for example the works of Giraud et al. (2008) on the micromechanical modelling of coupled porothermoelastic tensors, elastic stiffness, thermal expansion and Biot's tensors of 

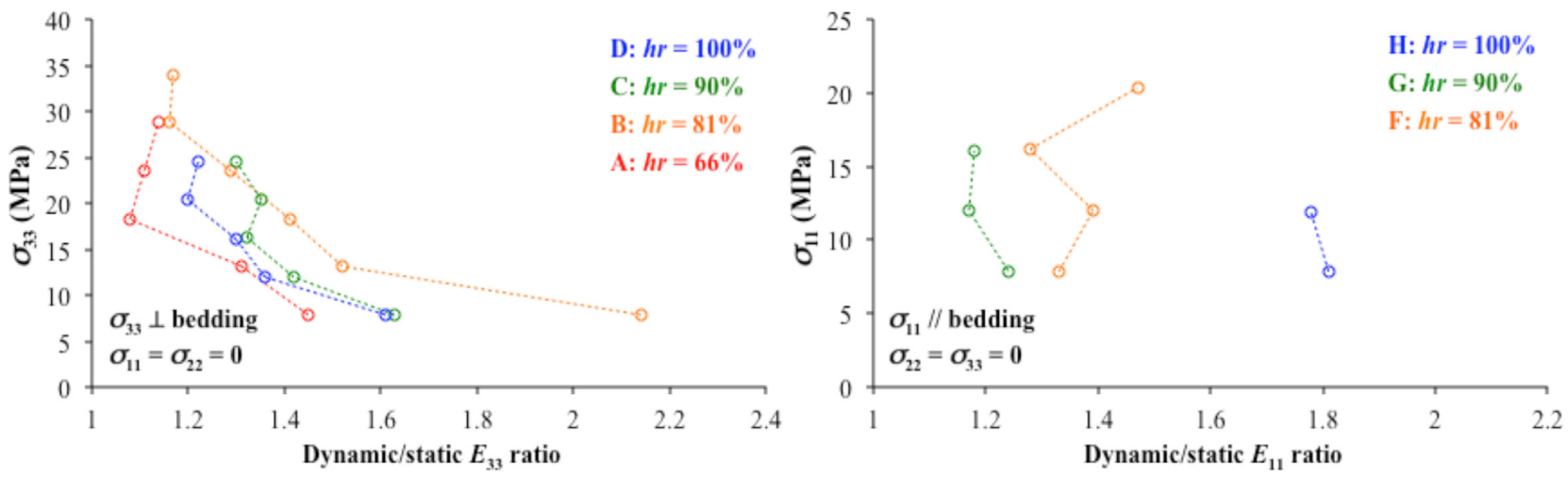

Figure 14. Dynamic/static (tangent method) Young's moduli ratio ( $E_{33}$ for perpendicular loading and $E_{11}$ for parallel loading) for all tested samples.

transversely isotropic rocks, and see the micromechanical analysis of Ortega (2010) and Ortega et al. (2010) on effective poroelastic properties of shale rocks. Because of the small pore size and low permeability of rocks containing clay minerals, it is very difficult to saturate samples and control pore pressure experimentally and then measure Biot's coefficient in laboratory. For this reason, there are only a few experimental studies about measurements of Biot's tensor on clay-rich rocks such as Callovo-Oxfordian claystone/argillites of Meuse/Haute Marne (e.g. Escoffier 2002; Bemer et al. 2004; Cariou et al. 2012; Cariou et al. 2013; Belmokhtar et al. 2016; Yuan et al. 2017) and shale (Ortega et al. 2010). For example, Yuan et al. (2017) have recently obtained, thanks to poromechanical tests using gas pressure technique, a quasi-isotropic Biot's tensor on an argillaceous transversely isotropic rock (Callovo-Oxfordian argillite from Paris sedimentary basin). Globally, it resulted from these experimental studies that Biot's tensor components are very close, at different values of water saturation. Then, it is reasonably considered that Biot's tensor is an isotropic property, i.e. represented by a scalar Biot's coefficient ( $b=0.9$ for the studied claystone). Taking into account these considerations, one can expect that for the perpendicular loading direction, microcracks that develop perpendicularly to the bedding plane by increasing pore space connectivity in this direction, reduce the anisotropy degree of the Biot's coefficients tensor. However, for the parallel loading direction, microcracks that develop in parallel to the bedding planes increase pore space connectivity mainly within these weakness planes and not in the whole material, which is expected to increase the anisotropy degree of the Biot's tensor.

\subsection{Influence of water}

The effects of water on the deformation and strength of rocks have already been demonstrated by many authors (e.g. Rutter 1972; Lajtai et al. 1987; West 1994; Baud et al. 2000; Grgic et al. 2005; Eslami et al. 2010). These effects may be both mechanical (hydromechanical coupling) and physicochemical (Rehbinder effects such as subcritical stress corrosion cracking, intergranular pressure solution). In the case of the tested claystone, because of its heterogeneity, the tendencies in the mechanical behaviour are sometimes difficult to identify. The influence of pore fluid pressure on the deformation and strength of porous rocks can be formulated using the effective stress concept. The total stress tensor may be decomposed into an effective stress tensor and a fluid pressure tensor. Within the framework of partially saturated porous media, the fluid pressure tensor is usually represented by the $\pi$ function (Coussy 1995), which corresponds to the equivalent interstitial pressure. Hence, the partition of the stress tensor and the mean stress for partially saturated porous media can be written as follows:

$\underline{\underline{\sigma^{\prime}}}=\underline{\underline{\sigma}}-b \pi \underline{\underline{1}} \quad \sigma_{m}^{\prime}=\sigma_{m}-b \pi$.

The $\pi$ function is expressed as follows (Coussy 1995):

$\pi=p_{\mathrm{g}}-\int_{0}^{p_{\mathrm{c}}} S_{l}(x) \mathrm{d} x=p_{g}-S_{l} p_{c}-\int_{S_{l}}^{1} p_{c}(x) \mathrm{d} x$,

where $S_{l}$ and $p_{g}$ are the liquid saturation and the gas (water vapour and dry air) pressure, respectively.

This function allows the generalization of the pore pressure in both saturated and partially saturated cases. $\pi$, which is calculated from the water sorption curves (Fig. 2, right-hand side), is equal to the liquid pressure in the saturated domain and is negative in the partially saturated domain.

Fig. 15 shows, in the space of effective stress invariants $\left(\sigma_{e q}\right.$, $\left.\sigma^{\prime}{ }_{m}\right)$ and in the $\left(\sigma_{e q}, h_{r}\right)$ plane, the failure points of the uniaxial compression tests on all samples. The two first invariants of the Cauchy stress tensor, the mean stress $\sigma_{m}$ and the shear stress (or Von Mises equivalent stress) $\sigma_{e q}$, are expressed as follows in triaxial conditions:

$\sigma_{m}=\frac{\sigma_{11}+\sigma_{22}+\sigma_{33}}{3} \quad \sigma_{e q}=\left|\sigma_{11}-\sigma_{33}\right|$

The uniaxial compression strength decreases globally with the increase in relative humidity $h_{r}$ and liquid saturation, as it was expected, even though the evolution is not monotonous for the perpendicular loading direction because of the claystone heterogeneity. Also, the strength in the parallel direction is systematically lower than the strength in the perpendicular direction, which is a usual result with anisotropic clayrocks.

Fig. 16 represents the stress-strains curves for all tested samples. Drying usually stiffens (decrease in deformability and increase in Young's modulus) rocks, as it was already shown in many past studies on limestone (e.g. Eslami et al. 2010) or argillite (e.g. Hoxha et al. 2007). In the case of the studied claystone, the behaviour is dependent on the loading direction. Indeed, when the direction of the uniaxial loading is perpendicular to the bedding plane, overall the drying induces an increase in material axial deformation and a decrease in static Young's modulus $E_{33}$ (Fig. 12), i.e. it softens the rock. The drying induces also a decrease in dynamic Young's modulus $E_{33}$ (Fig. 13). However, when the direction of the uniaxial loading is parallel to the bedding plane, the tendency is less obvious but it seems that the drying induces a decrease in material axial deformation and an increase in static (Fig. 12) and dynamic (Fig. 13) Young's modulus $E_{11}$. 

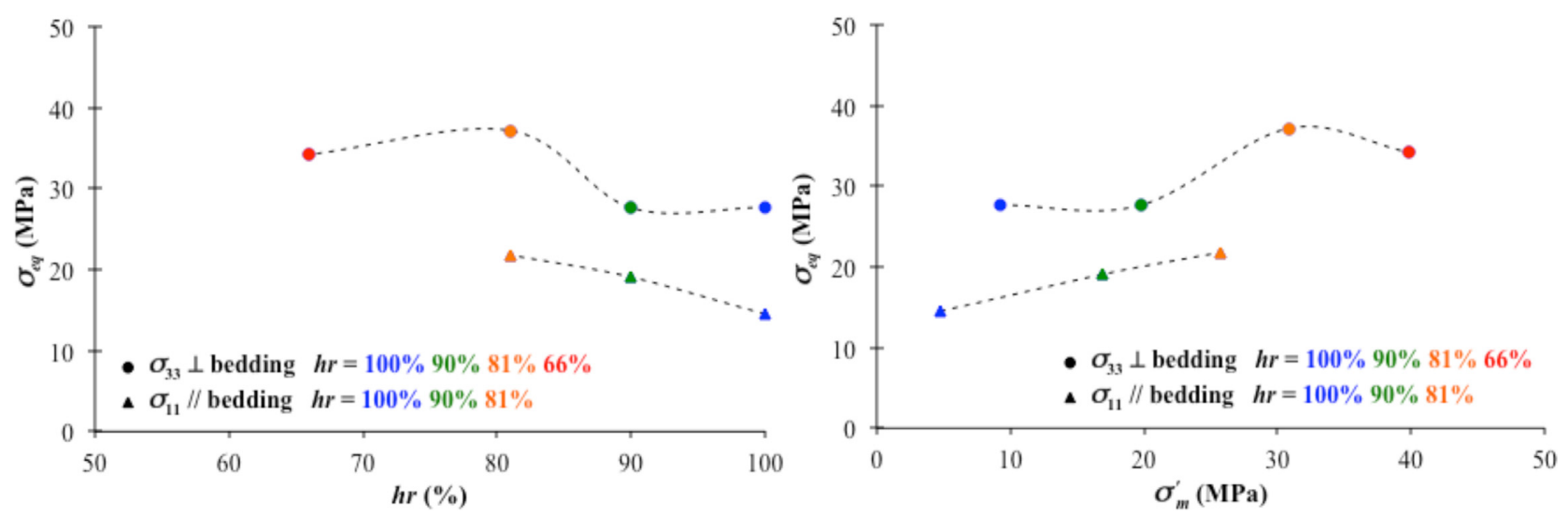

Figure 15. Failure points of all tested samples in $\left(\sigma_{e q}, \sigma^{\prime}{ }_{m}\right)$ and $\left(\sigma_{e q}, h_{r}\right)$ planes.
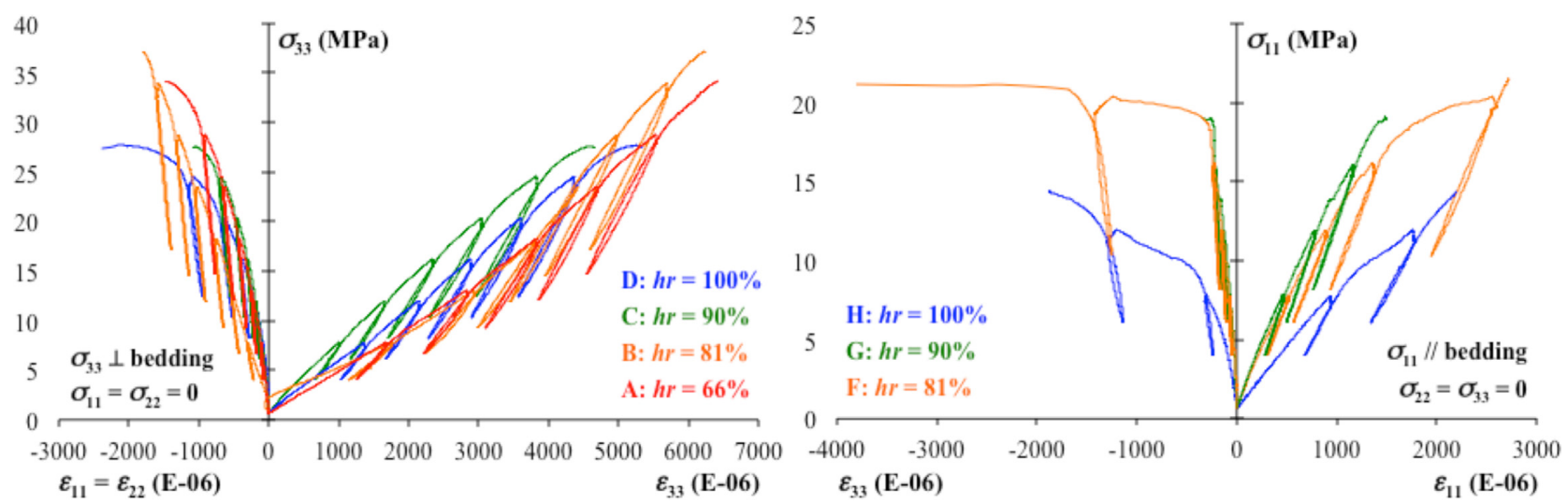

Figure 16. Stress-strains curves of all tested samples.

These evolutions can be explained by considering the whole impact of the drying on the behaviour of an anisotropic claystone, i.e. stiffening of the matrix and damage induced by cracks along the planes of weakness (bedding) due to preferred alignment of phyllosilicate minerals. The more the claystone is initially dried, the more the matrix is hardened and the damage significant. Indeed, as shown in Fig. 17, which represents the evolution of Thomsen's anisotropy parameters $(\varepsilon$ and $\gamma$ ) of all tested samples under bedding-perpendicular loading, the more the claystone is initially dried, the more the initial $P$-wave anisotropy $\varepsilon$ is high. This could be explained by the creation of cracks along planes of weakness (i.e. bedding planes) by the drying; then the material becomes semi-continuous. The initial $S$-wave anisotropy $\gamma$ seems to not be influenced by the drying. The variation of $\varepsilon$ parameter with humidity could also be the result of a simple drying of cracks and change of saturation ( $P$-waves are sensitive to fluid), without further cracking. This has been shown by Guéguen \& Sarout (2011) in a simpler case (isotropic matrix and aligned cracks) from a linear elastic modelling of the effect of pores and cracks orientation distribution on anisotropy and dispersion. Quasi-constant $\gamma$ parameter can be expected since it is lower than $\varepsilon$ parameter and does not change with saturation. In the case of the studied claystone, due to the lack of data on the microstructure (elastic anisotropic degree of solid matrix, initial pore and crack orientation distribution. .. ), it is difficult to conclude at the present between these two explanations.
For the perpendicular loading direction, the impact of the damage is predominant. The increase in axial stress $\sigma_{33}$ induces the closure of the cracks along horizontal bedding plane (axes 1 and 2) induced by the initial drying; then the more the sample is initially dried the more the axial strain is significant and the axial Young's modulus $E_{33}$ is small. This behaviour (softening with drying) is not intuitive and the opposite is usually found for similar rocks such as argillite (e.g. Hoxha et al. 2007; Zhang 2011). This could be explained by a higher sensibility to drying of the studied claystone. For the parallel loading direction, the impact of matrix hardening is predominant. The increase in axial stress $\sigma_{11}$ does not induce the closure of the cracks along vertical bedding planes (axes 1 and 2) induced by the initial drying; then the more the sample is initially dried the more the axial strain is small and the axial Young's modulus $E_{11}$ is significant.

\section{CONCLUSIONS}

Ultrasonic waves velocities were measured continuously on a transversely isotropic clayrock under uniaxial loading and different hydrous conditions. Two main directions for the application of the uniaxial stress, namely, parallel and perpendicular to the bedding plane, were considered. For both directions of loading, the evolution of $P$ - and $S$-wave velocities reproduces the shape and features of the stress-strain curves remarkably well. For the bedding-perpendicular 

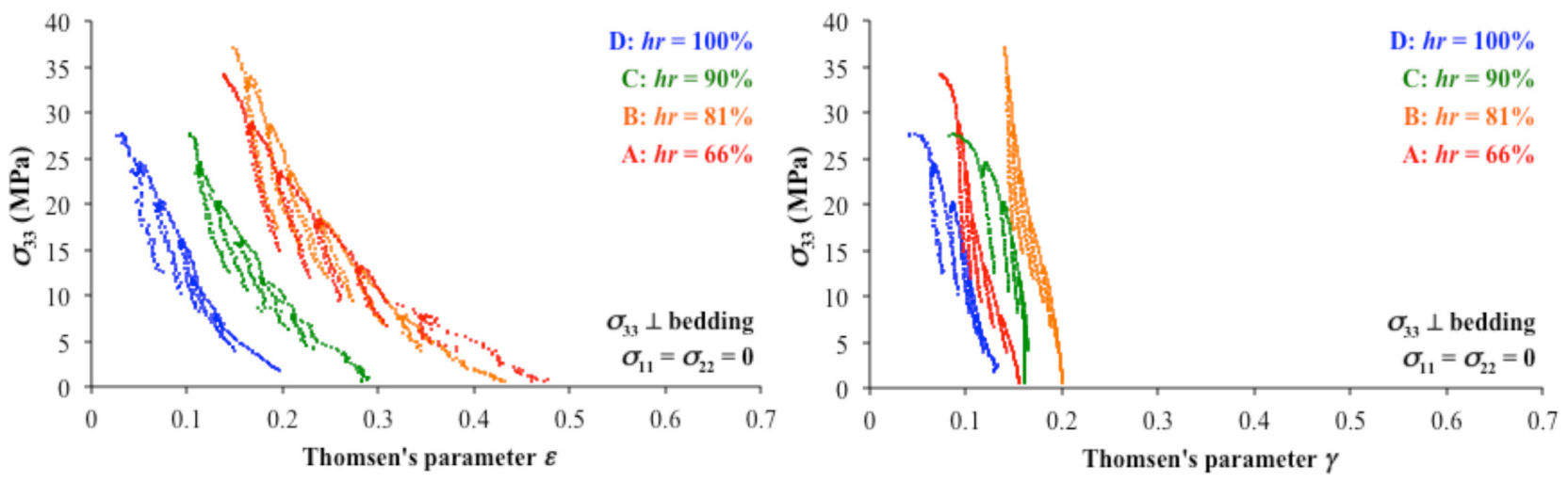

Figure 17. Evolution of Thomsen's anisotropy factors $(\varepsilon$ and $\gamma)$ of all tested samples under bedding-perpendicular loading.

loading direction, the axial strain, wave velocities and dynamic axial Young's modulus increase significantly with stress due to the stiffening of the crystals structure (tightening of clay and micas sheets aligned with the bedding plane) and grain contacts, and closure of microcracks and crack-like pores aligned with the bedding plane. For the bedding-parallel loading direction, the axial strain, $P$-wave velocity $V P_{0^{\circ}}$ and the dynamic axial Young's modulus increase only slightly and the behaviour is more linear because clay crystals structure is much less stiffened and pre-existing cracks aligned with the bedding plane remain open. From the onset of unstable growth of microcracks until the macroscopic failure of the sample, for the perpendicular loading direction, the decrease of $V P_{0^{\circ}}, V P_{\theta}$ and $V S h_{0^{\circ}}$ suggests that microcracks propagate in the vertical loading direction and their opening is parallel to the horizontal bedding plane. For the parallel loading direction, the decrease of $V P_{90^{\circ}}$ and $V P_{\theta}$ and strains evolution suggest that induced microcracks are aligned within the vertical bedding planes (i.e. planes of weakness) and their horizontal opening is perpendicular to these planes. The consequence of these irreversible mechanisms of deformation and damage is that the elastic anisotropy, initially significant, reduces markedly during perpendicular loading and increases during parallel loading. $P$-wave anisotropy evolves much more than $S$-wave anisotropy because $S$-waves travelling through clay-rich materials are relatively insensitive to stress change.

The dynamic Young's modulus is larger than the static one (up to 2.2 times) before loading. For the perpendicular loading direction, the ratio of dynamic to static moduli decreases continuously until the macroscopic failure. This could be explained by the development of microcracks in the direction perpendicular to the bedding plane that increase pore space connectivity in the same direction, which is expected to reduce the anisotropy of Biot's coefficients tensor. Hence, the microcracks, with initially sealed pore fluid because of the high frequency ultrasonic perturbation, would then hydraulically connect to the rest of the pore space, thus reducing the effective stiffness of the rock matrix. For the parallel loading direction, the ratio is almost constant. This suggests that induced microcracks increase pore space connectivity mainly within bedding planes (i.e. weakness planes) and not in the whole material, which probably increases the anisotropy of the Biot's tensor.

The uniaxial compressive strength of the studied anisotropic claystone, which is systematically lower in the parallel direction than in the perpendicular direction, decreases globally with the increase in water saturation. In addition, the drying softens the rock (increase in axial deformation and a decrease in dynamic and static axial Young's moduli) for the perpendicular loading direction and stiffens the rock for the parallel loading direction. This could be explained by the creation of cracks along bedding planes during initial drying. The more the claystone is initially dried, the more it is cracked, which increases initial $P$-wave anisotropy. For the perpendicular loading direction, the increase in axial stress induces a significant axial compaction due to the closure of these horizontal cracks. This behaviour (softening with drying) is not usual for this kind of rock, which could be explained by a higher sensibility to drying of the studied claystone. Contrariwise, for the parallel loading direction, the drying globally stiffens the rock.

The study of microcracking damage of a transversely isotropic clayrock using US wave velocity measurements, under variable loading direction and saturation, allows a better characterization of EDZ around underground manmade structures. Indeed, in such shallow environments, hydrous conditions evolve with time and have a significant impact on the mechanical behaviour of rocks. The analysis of differences between static and dynamic elastic moduli is of great interest in many geophysical and geomechanical applications. Indeed, conventional static measurements in the laboratory are not always possible due to the scarcity of rock samples and dynamic measurements are often more accessible from seismic surveys of sonic well logs in the field. The experimental results suggested by this analysis (increase in pore space connectivity and variations of the Biot's tensor anisotropy) could provide input data for modelling wave propagation in low permeability anisotropic clayrocks considering Biot's dynamic theory of poroelasticity and squirt-flow phenomenon.

\section{ACKNOWLEDGEMENTS}

This research was carried out thanks to subsidies from the Lorraine Region and CNRS-INSU (National Institute for Earth Sciences and Astronomy from National Center for Scientific Research of France). The authors express their gratitude to these organizations. We are also grateful to the reviewers, Yves Guéguen and Joël Sarout, for their constructive comments that helped to improve the quality of the manuscript. 


\section{REFERENCES}

Asef, M.R. \& Farrokhrouz, M., 2017. A semi-empirical relation between static and dynamic elastic modulus, J. Pet. Sci. Eng., 157, 359-363.

Atkinson, B.K., 1984. Subcritical crack growth in geological materials, $J$. geophys. Res., 89(B6), 4077-4114.

Atkinson, B.K. \& Meredith, P.G., 1987. The theory of subcritical crack growth with applications to minerals and rocks, in Fracture Mechanics of Rock, Academic press.

Baud, P., Zhu, W. \& Wong, T.-F., 2000. Failure mode and weakening effect of water on sandstone, J. geophys. Res., 105(B7), 16 371-316 389.

Belmokhtar, M., Delage, P., Ghabezloo, S., Tang, A.-M., Menaceur, H. \& Conil, N., 2016. Poroelasticity of the Callovo-Oxfordian claystone, Rock Mech. Rock Eng., 1-19.

Bemer, E., Longuemare, P. \& Vincké, O., 2004. Poroelastic parameters of Meuse/Haute Marne argillites: effect of loading and saturation states, Appl. Clay Sci., 26(1-4), 359-366.

Berryman, J.G., 1979. Long-wave elastic anisotropy in transversely isotropic media, Geophysics, 44(5), 896-917.

Bieniawski, Z.T., 1967. Mechanism of brittle fracture of rock, parts I, II, III, Int. J. Rock Mech. Min. Sci., 4, 395-430.

Biot, M.A., 1962. Generalized theory of acoustic propagation in porous dissipative media, J. acoust. Soc. Am., 34(5), 1254-1264.

Birch, F., 1960. The velocity of compressional waves in rocks to 10 kilobars, J. geophys. Res., 65, 1083-1102.

Brotons, V., Tomas, R., Ivorra, S., Grediaga, A., Martinez-Martinez, J., Benavente, D. \& Gomez-Heras, M., 2016. Improved correlation between the static and dynamic elastic modulus of different types of rocks, Mater. Struct., 49, 3021-3037.

Cariou, S., Dormieux, L. \& Skoczylas, F. 2013. An original constitutive law for Callovo-Oxfordian argillite, a two-scale double-porosity material, Appl. Clay Sci., 80-81, 18-30.

Cariou, S., Duan, Z., Davy, C., Skoczylas, F. \& Dormieux, L., 2012. Poromechanics of partially saturated COx argillite, Appl. Clay Sci., 56, 36-47.

Cheng, A.H.D., 2016. Poroelasticity, Springer.

Christaras, B., Auger, F. \& Mosse, E., 1994. Determination of the moduli of elasticity of rocks. Comparison of the ultrasonic velocity and mechanical resonance frequency methods with direct static methods, Mater. Struct., 27, 222-228.

Coussy, O., 1995. Mechanics of Porous Continua, 2nd edn, Wiley.

Coussy, O., 2004. Poromechanics, John Wiley and Sons.

Delle Piane, C., Dewhurst, D.N., Siggins, A.F. \& Raven, M.D., 2011. Stressinduced anisotropy in brine saturated shale, Geophys. J. Int., 184, 897906.

Dellinger, J. \& Vernik, L., 1994. Do traveltimes in pulse-transmission experiments yield anisotropic group or phase velocities? Geophysics, 59(11), 1774-1779.

Dewhurst, D.N., Raven, M.D., van Ruth, P., Tingate, P.R. \& Siggins, A.F., 2002. Acoustic properties of Muderong Shale, APPEA J., 42, 241-257.

Dewhurst, D.N. \& Siggins, A.F., 2006. Impact of fabric, microcracks and stress field on shale anisotropy, Geophys. J. Int., 165, 135-148.

Dewhurst, D.N., Siggins, A.F., Sarout, J., Raven, M.D. \& Nordgard-Bolas, H.M., 2011. Geomechanical and ultrasonic characterization of a Norwegian Sea shale, Geophysics, 76(3), WA101-WA111.

Dodds, K.J., Dewhurst, D.N., Siggins, A.F., Ciz, R., Urosevic, M., Gurevich, B. \& Sherlock, D.H., 2007. Experimental and theoretical rock physics research with application to reservoirs, seals and fluid processes, J. Pet. Sci. Eng., 57, 16-36.

Escoffier, S., 2002. Caractérisation expérimentale du comportement hydromécanique des argilites de Meuse/Haute-Marne, $P h D$ thesis, Nancy, France: École Nationale Supérieure de Géologie de Nancy; 2002.

Eslami, J., Grgic, D. \& Hoxha, D., 2010. Estimation of the damage of a porous limestone from continuous $(P$ - and $S$-) wave velocity measurements under uniaxial loading and different hydrous conditions, Geophys. J. Int., 183, 1362-1375.

Eslami, J., Hoxha, D. \& Grgic, D., 2012. Estimation of the damage of a porous limestone using continuous wave velocity measurements during uniaxial creep tests, Mech. Mater., 49, 51-65.
Fortin, J., Schubnel, A. \& Guéguen, Y., 2005. Elastic wave velocities and permeability evolution during compaction of Bleurswiller sandstone, Int. J. Rock Mech. Min. Sci., 42, 873-889.

Giraud, A., Hoxha, D., Huynh, Q.V., Do, D.P. \& Magnenet, V., 2008. Effective porothermoelastic properties of transversely isotropic rock-like composites, Int. J. Eng. Sci., 46(6), 527-550.

Grgic, D. \& Amitrano, D. 2009. Creep of a porous rock and associated acoustic emission under different hydrous conditions, J. geophys. Res., 114(Issue B10), 19,

Grgic, D., Giot, R., Homand, F. \& Giraud, A., 2005. Effect of suction on the mechanical behaviour of iron ore rock, Int. J. Num. Anal. Methods Geomech., 29(8), 789-827.

Grgic, D. \& Giraud, A. 2014. The influence of different fluids on the static fatigue of a porous rock: poro-mechanical coupling versus chemical effects, Mech. Mater, 71, 34-51.

Grgic, D., Giraud, A. \& Auvray, C., 2013. Impact of chemical weathering on micro/macro-mechanical properties of oolithic iron ore, Int. J. Rock Mech. Min. Sci., 64, 236-245.

Guéguen, Y. \& Sarout, J., 2011. Characteristics of anisotropy and dispersion in cracked medium, Tectonophysics, 503, 165-172.

Holt, R.M., Fjær, E., Raaen, A.M. \& Ringstad, C., 1991. Influence of stress state and stress history on acoustic wave propagation in sedimentary rocks, in: Shear Waves in Marine Sediments, pp. 167-174, eds Hovem, J.M., Richardson, M.D. \& Stoll, R.D., Kluwer.

Homand, F., Hoxha, D., Belem, T. \& Pons, M.N., 2000. Geometric analysis of damaged microcracking granites, Mech. Mater., 32, 361-376.

Hornby, B.E., 1998. Experimental laboratory determination of the dynamic elastic properties of wet, drained shales, J. geophys. Res., 103(B12), 29 945-29964.

Hoxha, D., Giraud, A., Homand, F. \& Auvray, C., 2007. Saturated and unsaturated behaviour modelling of Meuse-Haute/Marne argillite, Int. J. Plast., 23, 733-766.

Jakobsen, M. \& Johansen, T.A., 2000. Anisotropic approximations for mudrocks: a seismic laboratory study, Geophysics, 65, 1711-1725.

Jeong, H.-S., Kang, S.-S. \& Obara, Y., 2007. Influence of surrounding environments and strain rates on the strength of rocks subjected to uniaxial compression, Int. J. Rock Mech. Min. Sci., 44, 321-331.

Johnston, J.E. \& Christensen, N.I., 1995. Seismic anisotropy of shales, J. geophys. Res., 100(B4), 5991-6003.

Johnston, D.H. \& Toksöz, M.N., 1980. Ultrasonic $P$ and $S$ wave attenuation in dry and saturated rocks under pressure, J. geophys. Res., 85(B2), 925936.

Jones, L.E.A. \& Wang, H.F., 1981. Ultrasonic velocities in Cretaceous shales from the Williston basin, Geophysics, 46(3), 288-297.

Kranz, R., 1983. Microcracks in rocks: a review, Tectonophysics, 100(1-3), $449-480$.

Lajtai, E.Z., Schmidtke, R.H. \& Bielus, L.P., 1987. The effect of water on the time-dependent deformation and fracture of a granite, Int. J. Rock. Mech. Min. Sci. Geomech. Abstr., 24, 247-255.

Lo, T.-W., Coyner, K.B. \& Toksöz, M.N., 1986. Experimental determination of elastic anisotropy of Berea sandstone, Chicopee shale, and Chelmsford granite, Geophysics, 51(1), 164-171.

Meléndez-Martínez, J. \& Schmitt, D.R., 2016. A comparative study of the anisotropic dynamic and static elastic moduli of unconventional reservoir shales: implication for geomechanical investigations, Geophysics, 81(3), D245-D261.

Ortega, J.A., 2010. Microporomechanical Modeling of Shale, PhD thesis. Massachusetts Institute of Technology, Cambridge, MA.

Ortega, J.A., Ulm, F.J. \& Abousleiman, Y., 2010. The effect of particle shape and grain-scale properties of shale: a micromechanics approach, Int. J. Numer. Anal. Methods Geomech., 34(11), 1124-1156.

Pimienta, L., Fortin, J. \& Guéguen, Y., 2016. Effect of fluids and frequencies on Poisson's ratio of sandstone samples, Geophysics, 81(2), D35-D47.

Podio, A.L., Gregory, A.R. \& Gray, K.E., 1968. Dynamic properties of 16 dry and water-saturated green river shale under stress, J. Soc. Pet. Eng., 8(4), 389-404.

Rutter, E.H., 1972. The influence of interstitial water on the rheological behaviour of calcite rocks, Tectonophysics, 14, 13-33. 
Sarout, J., Cazes, E., Delle Piane, C., Arena, A. \& Esteban, L., 2017. Stressdependent permeability and wave dispersion in tight cracked rocks: experimental validation of simple effective medium models, J. geophys. Res., 122, 6180-6201.

Sarout, J., Delle Piane, C., Nadri, D., Esteban, L. \& Dewhurst, D.N., 2015. A robust experimental determination of Thomsen's $\delta$ parameter, Geophysics, 80(1), A19-A24.

Sarout, J., Esteban, L., Delle Piane, C., Maney, B. \& Dewhurst, D.N., 2014. Elastic anisotropy of Opalinus Clay under variable saturation and triaxial stress, Geophys. J. Int., 198, 1662-1682.

Sarout, J. \& Guéguen, Y., 2008a. Anisotropy of elastic wave velocities in deformed shales: Part 1 - Experimental results, Geophysics, 73(5), D75D89.

Sarout, J. \& Guéguen, Y., 2008b. Anisotropy of elastic wave velocities in deformed shales: Part 2 - Modeling results, Geophysics, 73(5), D91D103.

Sarout, J., Molez, L., Guéguen, Y. \& Hoteit, N., 2007. Shale dynamic properties and anisotropy under triaxial loading: experimental and theoretical investigations, Phys. Chem. Earth, 32(8-14), 896-906.

Sayers, C. \& Kachanov, M., 1995. Microcrack-induced elastic wave anisotropy of brittle rocks, J. geophys. Res., 100(B3), 4149-4156.

Sayers, C., Van Munster, J. \& King, M., 1990. Stress-induced ultrasonic anisotropy in Berea sandstone, Int. J. Rock Mech. Min. Sci. Geomech. Abstr., 27(5), 429-436.

Schubnel, A. \& Guéguen, Y., 2003. Dispersion and anisotropy of elastic waves in cracked rocks, J. geophys. Res., 108(B2).

Stanley, D. \& Christensen, N.I., 2001. Attenuation anisotropy in shale at elevated confining pressures, Int. J. Rock Mech. Min. Sci., 38, 1047-1056.

Thomsen, L., 1986. Weak elastic anisotropy, Geophysics, 51, 1954-1966.

Tsvankin, I., 2001. Seismic Signatures and Analysis of Reflection Data in Anisotropic Media, pp. 436, Pergamon Press.

Vanheerden, W.L., 1987. General relations between static and dynamic moduli of rocks, Int. J. Rock Mech. Min. Sci., 24, 381-385.

Vernik, L. \& Nur, A., 1992. Ultrasonic velocity and anisotropy of hydrocarbon source rocks, Geophysics, 57, 727-735.

West, G., 1994. Effect of suction on the strength of rock, Quart. J. Eng. Geol., 27, 51-56.

Yin, H., 1992. Acoustic velocity and attenuation of rocks: isotropy, intrinsic anisotropy, and stress-induced anisotropy, Ph.D. thesis, Stanford University, Stanford, USA.

Yuan, H., Agostini, F., Duan, Z., Skoczylas, F. \& Talandier, J., 2017. Measurement of Biot's coefficient for COx argillite using gas pressure technique, Int. J. Rock Mech. Min. Sci., 92, 72-80.
Zhang, F., 2011. Comportement mécanique des argilites de MHM - influences de la saturation, de la composition minéralogique et de la temperature, $P h D$ thesis, Université Lille I.

Zhao, Y., 1998. Crack pattern evolution and a fractal damage constitutive model for rock, Int. J. Rock. Mech. Min. Sci., 35(3), 349-366.

\section{APPENDIX: CALCULATION OF THE PHASE VELOCITY FOR THE OFF-AXIS $P$-WAVE}

For the calculation of the phase velocity $V P_{\theta}$, it is necessary to use the eigen solutions of the Christoffel's equation for transversely isotropic material (Tsvankin 2001; Dewhurst \& Siggins 2006):

$$
\left|\begin{array}{cc}
C_{11} \sin ^{2} \theta+C_{44} \cos ^{2} \theta-\rho V_{\theta}^{2} & \left(C_{13}+C_{44}\right) \cos \theta \sin \theta \\
\left(C_{13}+C_{44}\right) \cos \theta \sin \theta & C_{44} \sin ^{2} \theta+C_{33} \cos ^{2} \theta-\rho V_{\theta}^{2}
\end{array}\right|=(\mathbf{A}, 1)
$$

where $V_{\theta}$ is the phase velocity and $\theta$ is the phase angle, i.e. the angle of the wavefront normal with respect to the symmetry axis.

From that, one can obtain the following equation for the phase velocity of the $P$ - wave $V P_{\theta}$ travelling along phase angle $\theta$ (Tsvankin 2001):

$2 \rho V P_{\theta}^{2}=\left(C_{11}+C_{44}\right) \sin ^{2} \theta+\left(C_{33}+C_{44}\right) \cos ^{2} \theta$ $+\sqrt{\left(\left(C_{11}-C_{44}\right) \sin ^{2} \theta-\left(C_{33}-C_{44}\right) \cos ^{2} \theta\right)^{2}+4\left(C_{13}+C_{44}\right)^{2} \sin ^{2} \theta \cos ^{2}}$

Following Berryman (1979), the group (ray) angle $\phi$ (along which energy propagates), i.e. the angle from the source point to the wavefront, is obtained:

$\tan \phi=\frac{V_{\theta} \sin \theta+\frac{\partial V_{\theta}}{\partial \theta} \cos \theta}{V_{\theta} \cos \theta-\frac{\partial V_{\theta}}{\partial \theta} \sin \theta}$

Berryman (1979) also gave the relation between the scalar magnitude of the group velocity $V_{\phi}$ and the phase velocity magnitude $V_{\theta}$ :

$V_{\phi}^{2}=V_{\theta}^{2}+\left(\frac{\partial V_{\theta}}{\partial \theta}\right)^{2}$ 